\title{
Departamento de Física da UEFS: \\ sua natureza, diretrizes e perspectivas sob a ótica das considerações teórico-filosóficas consubstanciadas no seu projeto de criação.
}

\author{
Physics Department of UEFS:
}

its nature, lines of direction and perspectives under the point of view of the theoretical-philosophical considerations based in its project.

\author{
Franz A. Farias* e M.S.R. Miltão ${ }^{\dagger}$ \\ Departamento de Física - UEFS \\ Campus Universitário, Km 03, BR 116 \\ Feira de Santana - BA - 44031-460
}

\begin{abstract}
Neste trabalho, a partir do projeto de criação, analisamos a natureza, diretrizes e perspectivas do Departamento de Física da UEFS, sob a ótica das considerações teórico-filosóficas lá estabelecidas. Ao final, realizamos uma avaliação sobre a evolução do DFIS nesses cinco anos iniciais, considerando as atividades desenvolvidas pelo departamento à luz das diretrizes e perspectivas delineadas.
\end{abstract}

Palavras-chaves: Universidade, Unidade Acadêmica, Departamento, Política Educacional, Planejamento.

\begin{abstract}
Starting from the Physics Department Project (PDP), we make, in this work, an analysis about its nature, lines of direction and perspectives, under the light of the theoretical and philosophical considerations established in the PDP. To the end, we realize an evaluation of the progress of Physics Department through the first five years of its existence, taking the activities carry out in the Physics Department under the light of lines of direction and perspectives previously assumed.
\end{abstract}

Key-words: University, Academic Unit, Department, Educational Politics, Planning.

\section{INTRODUÇÃO}

Neste trabalho, a partir do projeto de criação, estabelecemos a natureza, diretrizes e perspectivas do Departamento de Física da UEFS, pinçando-as do conjunto da obra, para serem analisadas sob a ótica das considerações teóricofilosóficas lá consideradas.

O projeto de criação do Departamento de Física [1] foi aprovado pelo Conselho de Ensino, Pesquisa e Extensão da UEFS, através da resolução CONSEPE 69/98 [2] e o departamento foi implantado, conforme o projeto, pelo Conselho Universitário da UEFS, através da resolução CONSU $01 / 2000$ [3].

Do ponto de vista da estrutura deste trabalho, inicialmente, estabelecemos os princípios filosóficos relativos à teoria do conhecimento e à universidade que nortearam o projeto e que serviram de base para a definição de Unidade Acadêmica e Departamento.

Em um segundo momento, após caracterizar a Física como uma ciência, estabelecer a sua definição e caracterização do ponto de vista filosófico como um campo do saber, classificamos os seus sub-domínios, seguindo o espírito do projeto de criação.

Na seção sobre o Departamento de Física resumimos os principais fatos relacionados com a sua natureza, definição e objetivos para estabelecer a nova proposta de estrutura acadêmico-administrativa adotada e sistematizar as diretrizes e perspectivas que foram delineadas.

\footnotetext{
*Endereço Eletrônico: franz\_farias@terra.com.br

†Endereço Eletrônico: miltaaao@ig.com.br
}

Ao final, realizamos uma avaliação sobre a evolução do Departamento de Física (DFIS) da UEFS nesses cinco anos iniciais, considerando as atividades desenvolvidas pelo departamento à luz das diretrizes e perspectivas delineadas.

\section{PRESSUPOSTOS}

Na idealização do Departamento de Física da Universidade Estadual de Feira de Santana, conforme estabelecido em seu projeto de criação [1], alguns princípios, considerados inalienáveis, foram assumidos:

(i) O conhecimento é uma faculdade, normalmente irredutível à afetividade e à atividade, que indica a função da alma, assim como o resultado dessa função, de tornar compreensível-concebível um objeto (interno ou externo), obtendo dele um juízo ou uma representação [4]. Como o resultado dessa função, o conhecimento é um produto do processo de produção da existência humana; é um produto do "(...) processo histórico, que tem sua existência manifesta num comportamento cosmológico do indivíduo como parte de um todo social" [5];

(ii) Devemos estabelecer as condições e limites do próprio conhecimento como um guia do espírito humano em busca da verdade, sendo que, “... na realidade, as condições e limites do conhecimento não podem ser descobertos senão por uma volta da inteligência às suas próprias operações, no exercício (...) da obtenção do saber [6]";

(iii) O conhecimento, como produto do processo da existência humana, historicamente determinado a partir 
das necessidades de crescimento, evolução e desenvolvimento da humanidade, é tão vasto e tão amplo que "a fraca inteligência humana não [o] pode abranger. Daí a necessidade de fragmentar o conjunto de imensos conhecimentos que se propunham dar a explicação universal das coisas" [4]. Conseqüentemente, estabeleceram-se os Saberes Particulares, ou Campos do Saber, ou Disciplinas, entre os quais foram distribuídos todos os conhecimentos, segundo o critério de seu objeto;

(iv) O campo do saber é um conjunto sistematizado de conhecimentos relativos a um grupo de fenômenos ou objetos $[4,7]$, i.e., relativos a fenômenos ou objetos que manifestam propriedades em comum, sendo que tais conhecimentos são sistematizados a partir de investigação especializada a qual consiste em fazer surgir novos conhecimentos que substituem a outros mais antigos;

(v) A Universidade é uma Instituição que elabora, transmite e preserva o complexo, vasto e diverso conhecimento humano, e que deve comprometer-se em ser um agente do próprio processo da sociedade, enquanto uma força transformadora desta;

(vi) A organização natural da Universidade será aquela que leve em conta a própria concepção do saber humano, traduzindo e ecoando a sua diversidade, hiperdimensionalidade e complexidade.

Dessa forma, a luta pela concretização do Departamento de Física teve como pilar fundamental a crença, compartilhada por muitos, de que na UEFS a estrutura departamental, enquanto Unidade Acadêmica, deveria naquele momento representar-materializar cada elemento da diversidade-complexidade do saber humano, um dado campo do saber, de tal forma que a base geradora do conhecimento fosse estabelecida no interior da Universidade, garantindo, portanto, o equilíbrio sadio entre o espírito científico e o cultivo das letras, das artes e da filosofia. Não obstante, esse pilar fundamental não foi pensado estaticamente o que significa que, com o processo de crescimento natural da UEFS, outras estruturas mais apropriadas deverão ser utilizadas para representar-materializar o respectivo campo do saber, enquanto Unidade Acadêmica.

Também, vale citar que a criação do Departamento de Física constituiu-se em um primeiro passo para o questionamento da estrutura organizacional que a UEFS, baseada no modelo binário (Administração Superior - Departamentos) e no seu pequeno porte (pequeno número de departamentos), até então apresentava.

De fato, como exarado no parecer da Professora Raquel de Matos Cardoso do Vale (DCHF-UEFS), que avaliou o projeto de criação do Departamento de Física, em 1998 [2], "a UEFS hoje é uma instituição que ascende cada vez mais no cenário das universidades brasileiras, adquirindo credibilidade e respeitabilidade, fruto exatamente da efervescência de suas atividades acadêmico-científicas. Rever sua estrutura é, portanto, uma tarefa premente e que, mais cedo ou mais tarde, deveremos assumi-la".

O pilar fundamental, aludido mais acima, se baseia na premissa de que a Universidade, enquanto uma Instituição Educacional Hiperdimensional, organizada em Departamentos por campo do saber, responsável pela produção e transmissão dos conhecimentos transformadores da sociedade, estabelecidos a partir das necessidades, histórica e socialmente determinadas, será o berço do qual emergirá o pensamento complexo, fruto da reflexão crítica, fortalecido contra a crença de que o real se pode deixar fechar na idéia, ou se pode esgotar apenas nos princípios da razão, ou se pode essencialmente ser representado, ser objetivado, cônscio de que a complexidade surge como dificuldade, como incerteza e não como uma clareza e/ou como resposta.

Como apropriadamente coloca a Profa. Marilena Chauí [8]: "Qual é a especificidade e o bem mais precioso da Universidade? Ser ela uma Instituição social constituída por diferenças internas que correspondem às diferenças dos seus objetos de trabalho, cada qual com uma lógica própria de docência e de pesquisa (...)", portanto, continua a Profa. Chauí, "(...) a peculiaridade e a riqueza da Instituição [Universitária] estão justamente na ausência de homogeneidade, pois os seus objetos de trabalho são diferentes e regidos por lógicas, práticas e finalidades diferentes" [8].

Assumiu-se [1], portanto, que o Departamento na UEFS, deveria ser concebido como uma Unidade Acadêmica que representasse-materializasse um dado campo do saber, de tal forma que incorporasse o conjunto de disciplinas curriculares afins a este 'campo', congregando professores para objetivos comuns de Ensino, Pesquisa e Extensão.

\section{O CAMPO DO SABER DA FÍSICA}

Os diversos conhecimentos, distribuídos entre os campos do saber, constituem o Patrimônio da Humanidade. Eles "são produtos de, e exprimem as, relações que o ser humano estabelece com a natureza na qual se insere" [9].

Entre as relações que o ser humano estabelece com a natureza (i.e., com o universo), estão aquelas investigadas e sistematizadas no campo do saber da Física. Tal 'campo', sendo um dos campos do saber científico, possui um objeto próprio, um método, e um conjunto de hipóteses e teorias, sendo também inseparável do contexto social e histórico.

Dessa forma, definiu-se a Física como "o estudo do comportamento e da constituição do Universo, com o objetivo de descrevê-lo; portanto, é o conjunto sistematizado de conhecimentos científicos que objetivam estabelecer a origem, evolução e estrutura da matéria e da radiação do Universo, e cujo método passa pelas dificuldades do teste, da verificação, da relação entre as teorias e a realidade empírica, e da validação das descrições, previsões e aplicações" [1].

A caracterização da natureza [7] do campo do saber da Física foi dada pelos seguintes critérios:

- Domínio de Fenômenos ou Material: são aqueles fenômenos ou objetos que se manifestam como matéria e radiação do Universo e que estão ligados ao seu comportamento e constituição;

- Domínio de Estudo: é aquele caracterizado pela investigação do comportamento e constituição da matéria e da radiação do Universo e que é composto de conceitos, axiomas, postulados, definições, leis, teoremas e teorias;

- Níveis de Integração Teórica dos Conceitos Fundamentais e Unificadores: são aqueles que têm como base teorias e leis gerais (que relacionam 
os conceitos fundamentais e unificadores) e que permitem a integração teórica (do campo do saber da Física) com vistas a uma reconstrução da 'realidade' do Domínio de Estudo, a fim de descrever e prever os fenômenos por ele referidos. As teorias e leis gerais que, atualmente, servem de base aos níveis de integração teórica do campo do saber da Física são as seguintes [10]: Mecânica Clássica, Eletromagnetismo, Termodinâmica, Mecânica Estatística, Relatividade, e Mecânica Quântica;

- Métodos Próprios: na descrição dos fenômenos físicos, visando estabelecer todas as suas teorias e leis (em particular as teorias e leis gerais), é utilizada primordialmente a indução, para ascender dos fatos às leis fundamentais (embora não seja excluída, em vários momentos, a dedução, para descer das leis fundamentais e iluminar posteriormente os fatos, para compreendê-los melhor). Para implementá-la, são empregados os processos da Observação e da Experimentação. A Observação, sendo o exame do fenômeno buscando determinar as características básicas que o envolvem; a Experimentação, sendo a manipulação-provocação de situações visando o estabelecimento-verificação de todas as suas teorias e leis. O método próprio do campo do saber da Física, portanto, é subdividido em quatro fases: observação, formulação de uma hipótese diretriz, experimentação e indução;

- Instrumentos de Análise: na construção dos modelos para descrever os fenômenos observados, são utilizadas teorias matemáticas, as quais fazem com que tais modelos propostos, através de estruturas lógicas e raciocínios matemáticos, incorporem os resultados experimentais e façam previsões de novas situações;

- Aplicações: o campo do saber da Física tem uma vasta aplicação profissional na medida em que seus métodos teóricos e experimentais são aplicados na Tecnologia de Materiais, Tecnologia dos Equipamentos, Biologia, Saúde, Química, Geografia, Geologia, Agronomia, Zootecnia, Economia, Arquitetura, Urbanismo, Paleontologia, Arqueologia, Comunicação, Artes, dentre outras Disciplinas. Quanto mais as aplicações se estabelecem, mais eclético o campo do saber da Física se revela em sua concepção epistemológica, exigindo programas supradisciplinares;

- Contingências Históricas: em seu processo de evolução histórica, o campo do saber da Física se encontra, em cada fase, num momento de transição, em contato com ações e influências internas e externas do 'aqui' e do 'agora'. Para tais estudos e pesquisas, a Física utiliza os campos do saber da Matemática, das Letras, da Sociologia, da História e da Filosofia com o objetivo de contextualizar histórica e filosoficamente os seus produtos, i.e., os seus conhecimentos.
Portanto, de forma mais direta, pode-se afirmar, acompanhando Resende [11], que "a Física é o campo da ciência que investiga os fenômenos e as estruturas mais fundamentais da natureza, [i.e., do Universo], procurando sua compreensão e descrição em termos de leis as mais gerais possíveis" [11]. A Física estuda desde as partículas elementares, que são consideradas como os menores sistemas físicos, até o Universo, que é o maior.

"No processo de compreensão da natureza, as investigações físicas têm possibilitado o domínio de fenômenos naturais bem como a criação de fenômenos, materiais e sistemas artificiais que têm contribuído decisivamente para o avanço de outros campos" [11], ou seja, para o progresso filosófico, científico, artístico, literário, tecnológico e técnico da humanidade, contribuindo, assim, para a Universalidade do Saber.

Exemplos destas contribuições são:

- As investigações dos fenômenos eletromagnéticos, as quais levaram à invenção do gerador e do motor elétrico, do rádio, da televisão, do radar e dos sofisticados meios de comunicações tão fundamentais para a sociedade contemporânea;

- As investigações dos fenômenos microscópicos, as quais permitiram erigir a teoria quântica que originou a invenção do transistor, em 1947, e dos circuitos integrados, no final da década de 50 do Século XX, estes, por sua vez, responsáveis pela disseminação dos computadores que tanto têm transformado os costumes da sociedade;

- As investigações dos fenômenos nucleares, que tanto têm contribuído em campos importantes da atividade humana, tais como a Medicina, a Biologia, dentre outros;

- As investigações dos fenômenos sociológicos bem como econômicos, que permitem contribuir no estudo e análises do comportamento humano e social; e,

- As investigações dos fenômenos astronômicos, que permitem ponderações histórico-filosóficas sobre a origem da vida, do Universo e sobre o seu futuro.

\section{A. Os sub-domínios da Física}

Por ser um campo extremamente sofisticado da ciência e considerando o recorte de seu objeto de investigação, o método de abordagem, a necessidade de transmissão de seus resultados, a sua contextualização históricofilosófica, bem como a sua aplicação em outros campos do saber, assumiu-se para a Física investigada na atualidade, uma subdivisão apropriada, concebida em vários subdomínios [1]. Seguindo o espírito de [1], são eles [11]-[19]: 
Tab. I: Sub-Domínios e Áreas de Atuação

\begin{tabular}{|c|c|}
\hline Sub-Domínios & Áreas de Atuação \\
\hline (i) Física de Partículas e Campos & $\begin{array}{l}\text { Teoria de Campos, } \\
\text { Teorias de Ação à Distância, } \\
\text { Fenomenologia das Partículas Elementares, } \\
\text { Física Experimental de Altas Energias. }\end{array}$ \\
\hline (ii) Física Nuclear & $\begin{array}{l}\text { Teoria e Estrutura Nuclear, } \\
\text { Propriedades de Núcleos, } \\
\text { Desintegração Nuclear e Radioatividade, } \\
\text { Reações Nucleares e Espalhamento, } \\
\text { Estudos da Potência Nuclear. }\end{array}$ \\
\hline (iii) Física Atômica e Molecular & $\begin{array}{l}\text { Teoria e Estrutura Atômica e Molecular, } \\
\text { Propriedades Atômicas e Moleculares, } \\
\text { Processos de Confinamento e Colisões, } \\
\text { Espectroscopia e Aplicações, } \\
\text { Estudos de Átomos e Moléculas Especiais. }\end{array}$ \\
\hline (iv) Física de Plasmas & $\begin{array}{l}\text { Teoria de Plasmas, } \\
\text { Propriedades de Plasmas, } \\
\text { Fluxo de Plasmas, } \\
\text { Oscilações, Ondas e Instabilidade em Plasmas, } \\
\text { Produção e Aquecimento de Plasmas, } \\
\text { Confinamento e Equilíbrio de Plasmas, } \\
\text { Plasma Relativístico, } \\
\text { Descargas Elétricas. }\end{array}$ \\
\hline (v) Física da Matéria Condensada & $\begin{array}{l}\text { Teoria e Estrutura da Matéria Condensada, } \\
\text { Propriedades dos Gases, Líquidos e Sólidos, } \\
\text { Superfícies, Interfaces, Filmes e Fios Finos, } \\
\text { Dinâmica de Rede, } \\
\text { Processos de Transferência e Transporte em Matéria Condensada, } \\
\text { Magnetismo e Materiais Magnéticos, } \\
\text { Eletricidade e Propriedades Elétricas dos Materiais, } \\
\text { Semicondutores, } \\
\text { Supercondutividade e Superfluidez, } \\
\text { Espalhamento, } \\
\text { Técnicas de Caracterização de Materiais, } \\
\text { Mecânica dos Meios Contínuos. }\end{array}$ \\
\hline (vi) Astronomia & $\begin{array}{l}\text { Astrometria, } \\
\text { Mecânica Celeste, } \\
\text { Física do Sol, } \\
\text { Sistema Solar, } \\
\text { Astrofísica Estelar, } \\
\text { Astrofísica Galáctica, } \\
\text { Astrofísica Extragaláctica, } \\
\text { Cosmologia. } \\
\end{array}$ \\
\hline (vii) Instrumentação e Técnicas de Laboratório em Física & $\begin{array}{l}\text { Metrologia, } \\
\text { Medidas e Medições de Grandezas Físicas, } \\
\text { Técnicas Gerais de Laboratório, } \\
\text { Instrumentos, Aparatos e Componentes, } \\
\text { Instrumentação Computacional, } \\
\text { Instrumentação Eletromagnética Básica, } \\
\text { Instrumentação Espacial Básica, } \\
\text { Sistemas de Controle, } \\
\text { Manutenção, } \\
\text { Segurança do Trabalho. }\end{array}$ \\
\hline (viii) Física Matemática & $\begin{array}{l}\text { Teorias Matemáticas, } \\
\text { Métodos Matemáticos da Física, } \\
\text { Física Computacional, } \\
\text { Teorias e Leis Gerais da Física, } \\
\text { Axiomática das Teorias Físicas, } \\
\text { Sistemas Dinâmicos, } \\
\text { Complexidade, Caos e Fractais. }\end{array}$ \\
\hline (ix) Ensino de Física & $\begin{array}{l}\text { Materiais e Métodos, } \\
\text { Concepções Alternativas, } \\
\text { Metodologias Alternativas, } \\
\text { Processo Ensino-Aprendizagem, } \\
\text { Comunicação em Física, } \\
\text { Política Educacional. } \\
\end{array}$ \\
\hline
\end{tabular}




\begin{tabular}{|c|c|}
\hline Matéria & Disciplinas \\
\hline (x) História e Filosofia da Física & $\begin{array}{l}\text { História da Física, } \\
\text { Espaço e Tempo na História da Física, } \\
\text { Historiografia da Física, } \\
\text { Biografia, } \\
\text { Filosofia da Física, } \\
\text { Fundamentos da Física, } \\
\text { Análise de Textos Científicos de Física, } \\
\text { Política Científica e Tecnológica. } \\
\end{array}$ \\
\hline (xi) Física Aplicada & $\begin{array}{l}\text { Física dos Materiais, } \\
\text { Física dos Equipamentos, } \\
\text { Engenharia Física, } \\
\text { Física Aplicada à Química, } \\
\text { Física Aplicada à Farmácia, } \\
\text { Física Biológica, } \\
\text { Física Médica, } \\
\text { Física dos Esportes, } \\
\text { Física Aplicada à Geografia, } \\
\text { Geofísica, } \\
\text { Física da Atmosfera, } \\
\text { Física dos Oceanos, } \\
\text { Energia e sua Aplicação, } \\
\text { Física Aplicada à Arqueologia, } \\
\text { Física Aplicada à Antropologia Etnofísica, } \\
\text { Física Aplicada à Paleontologia, } \\
\text { Física Aplicada à Sociologia, } \\
\text { Física Aplicada à Economia, } \\
\text { Física Aplicada à Segurança Pública e Militar, } \\
\text { Física Agropecuária, } \\
\text { Física Aplicada ao Urbanismo, } \\
\text { Física do Meio Ambiente, } \\
\text { Física Aplicada à Comunicação, } \\
\text { Física Aplicada às Artes, } \\
\text { Física Aplicada aos Sistemas Complexos e Caóticos. }\end{array}$ \\
\hline
\end{tabular}

Os sub-domínios (i) até (vi), correspondem ao recorte do objeto de investigação da Física. Tal recorte vai do menor sistema físico - as partículas elementares - até o maior - o Universo. "Nesse percurso do microcosmo ao macrocosmo passa-se de dimensões de $10^{-15} \mathrm{~cm}$ (raio do próton) até o tamanho de uma galáxia $\left(10^{21} \mathrm{~m}\right)$ ou do Universo $\left(10^{25} \mathrm{~m}\right)$ " [16]. Portanto, nesses sete recortes, a Física investiga desde partículas elementares, subatômicas, átomos e moléculas, até fenômenos que envolvem grandes aglomerados delas, como a matéria ordinária em suas quatro formas de agregação e o próprio Universo.

Os sub-domínios (vii) e (viii), correspondem ao método de abordagem da Física: a Instrumentação e Técnicas de Laboratório em Física, leva em conta a abordagem experimental no que concerne a viabilização da atividade experimental, através do exame e aperfeiçoamento dos processos de observação e de experimentação, bem como na concepção e manutenção de instrumentos e técnicas laboratoriais; a Física Matemática, leva em conta a abordagem teórica no que concerne a viabilização da atividade teórica, através do exame e aperfeiçoamento das teorias físicas e de sua linguagem de trabalho, a Matemática, bem como através do estabelecimento da axiomática de tais teorias físicas.

O sub-domínio (ix), corresponde à necessidade de transmissão do conhecimento físico, e leva em conta que tal conhecimento, juntamente com os outros, constitui o Patrimônio da Humanidade.

O sub-domínio (x), corresponde à contextualização histórico-filosófica do conhecimento físico, e leva em conta que o sujeito produtor de tal conhecimento bem como o seu objeto de investigação, são espacial e historicamente determinados e, portanto, o conhecimento daí gerado será ideologicamente comprometido.

O sub-domínio (xi), corresponde à aplicação do campo do saber da Física em outros campos do saber, e leva em conta a busca da supradisciplinaridade, através da conjunção da Física com outros campos da Ciência, das Artes e da Tecnologia.

Os sub-domínios (vii), (viii), (ix), (x) e (xi) buscam, portanto, desenvolver a supradisciplinaridade nas suas diversas formas $[7,20,21]$ : multidisciplinaridade (como uma justaposição através da informação, sem cooperação metodológica), pluridisciplinaridade (como uma justaposição através da informação, com cooperação metodológica, mas sem coordenação), disciplinaridade cruzada (como uma justaposição através da permuta de informações, i.e., interação, com cooperação, mas sem coordenação), interdisciplinaridade (como uma redução através da interseção, com cooperação e coordenação) e transdisciplinaridade/metadisciplinaridade (como uma unificação através da comunicação, com cooperação e coordenação para uma visão comum, total).

Com isso, a Física se consubstancia como um dos legítimos campos do saber, contribuindo na construção da parede do conhecimento e na estruturação do conhecimento como Patrimônio da Humanidade. 


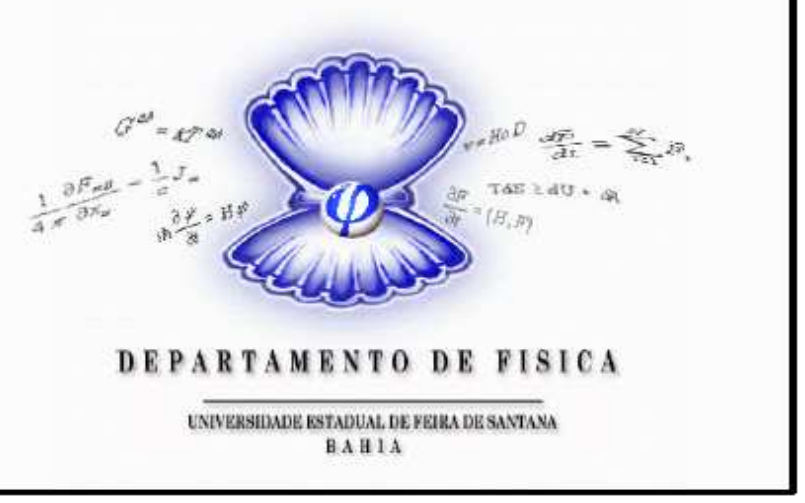

Fig. 1: Logotipo do DFIS, concebido por Elder S. Teixeira, Rosa Bunchaft e Thierry J. Lemaire

Do Brasão de Armas da Universidade Estadual de Feira de Santana, com sua quaterna de vieiras, buscou-se a concha. Da pérola, lá concebida, que per si reflete o próprio conhecimento produzido nesta Universidade, emana, como uma de suas luzes, a Física, simbolizada pelo $\varphi$ (de physis 'natureza', em grego [22]), e sintetizada por sete emblemáticas equações, que da concha se projetam para o exterior, como pretende-se que este campo do saber se difunda aos estudantes e à sociedade: $\grave{a}$ esquerda, de cima para baixo, a equação de Einstein da Relatividade Geral; a forma quadritensorial das equações de Maxwell, do Eletromagnetismo; a equação de Schroedinger, da Mecânica Quântica. À direita, de cima para baixo, a lei de Hubble, que expressa a velocidade de afastamento das galáxias; a segunda lei de Newton, da Mecânica Clássica; as primeira e segunda leis da Termodinâmica reunidas; e a equação de Liouville da Mecânica Estatística.

\section{O DEPARTAMENTO DE FÍSICA DA UEFS}

Estabelecidas, ainda que ingenuamente, as considerações teórico-filosóficas do conhecimento humano em geral e do conhecimento físico em particular, o substrato para as proposições relativas à natureza, diretrizes e perspectivas da unidade acadêmica Departamento de Física foi colocado.

Definiu-se o Departamento de Física como "a Unidade Acadêmica que representa-materializa o campo do saber da Física, de tal forma que incorpora o conjunto de disciplinas curriculares afins a este 'campo', congregando professores para objetivos comuns de Ensino, Pesquisa e Extensão em Física" [1].

Os objetivos gerais do Departamento de Física foram estabelecidos como:

- Representar-Materializar o campo do saber da Física,

- Incorporar o conjunto de disciplinas curriculares afins ao campo do saber da Física,
- Congregar professores para metas comuns de Ensino, de Pesquisa e de Extensão no campo do saber da Física,

- Ser um dos elementos da base geradora do pensamento-conhecimento humano complexo,

- Estimular, no campo da Física, a criação de grupos de pesquisa e extensão buscando as formas de supradisciplinaridade e o intercâmbio com os grupos de pesquisa e extensão consolidados.

Por sua vez, para os seus objetivos específicos tem-se:

- Consolidar o Ambiente Acadêmico propiciado a partir das implementações das ações delineadas no PCADFIS [23],

- Imprimir uma Identidade Acadêmica aos seus professores,

- Adotar e implementar políticas claras de produção e transmissão do conhecimento científico de Física, o que só é possível dentro de um Departamento forte e coeso, numa perspectiva extensionista de alcance social, outorgando à Universidade uma função transformadora da sociedade,

- Garantir a implementação (através de uma programação e execução efetivas) das atividades de ensino, pesquisa e extensão, dando ao DFIS-UEFS uma Personalidade Acadêmica clara e inconfundível, e,

- Contribuir para que as aspirações de crescimento da UEFS, reveladas na Avaliação Institucional [24] e no Planejamento Estratégico [25], tornem-se realidade, na medida em que o seu porte, assumido como pequeno no passado [24], [26], [27], deve ser modificado, possibilitando à UEFS assumir o efetivo perfil, tão almejado, de uma Universidade com pluridisciplinaridade de pesquisa, de extensão, e de formação de profissionais de nível superior.

Sob os auspícios de que a Universidade é uma instituição cujos pilares são as atividades de ensino, pesquisa e extensão, e que estas obedecem ao princípio da indissociabilidade, no projeto de criação do DFIS foi estabelecido que as estruturas acadêmica e administrativa de uma Universidade devem estar relacionadas com tais atividades. A estrutura acadêmica sendo aquela que dará a organização, o suporte para que as atividades de ensino, pesquisa e extensão, denominadas atividades fins, se desenvolvam; a estrutura administrativa sendo aquela que ajudará, auxiliará e coordenará aquelas atividades acadêmicas, através das atividades administrativas, denominadas atividades meio.

Em relação ao Departamento de Física da UEFS, conseqüentemente a sua Estrutura Acadêmico-Administrativa foi concebida como segue, de acordo com a Figura 2: 


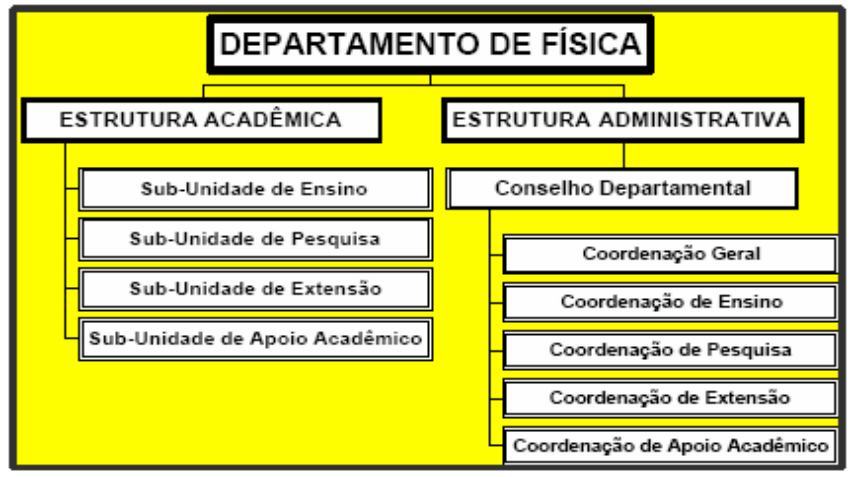

Fig. 2: Organograma do DFIS

Estrutura Acadêmica: é constituída pelas SubUnidades de Ensino, de Pesquisa, de Extensão, e de Apoio Acadêmico que congregam as respectivas atividades acadêmicas desenvolvidas pelo DFIS, dando, portanto, o suporte, a organização para que tais atividades se estabeleçam;

Estrutura Administrativa: é constituída pelo Conselho Departamental, Coordenação Geral, Coordenação de Ensino, Coordenação de Pesquisa, Coordenação de Extensão, e Coordenação de Apoio Acadêmico que congregam as respectivas atividades administrativas, dando, portanto, a ajuda, o auxílio, a coordenação para que as atividades acadêmicas ocorram.

Dessa forma, a docência foi assumida como o desenvolvimento, pelos professores, das atividades de ensino, de pesquisa, de extensão, e administrativa, o que garantirá de acordo com [1] a manutenção de tal Estrutura Acadêmico-Administrativa. O Departamento de Física, conseqüentemente, estimulará o conjunto de seus professores a desenvolver as três atividades fins, e não se furtará em estabelecer a importância do desenvolvimento da atividade administrativa, atividade meio, para que cumpram plenamente a ação da docência.

Para que tal plenitude seja efetivamente atingida, o que garantirá a manutenção da Estrutura AcadêmicoAdministrativa, o regime de trabalho dos professores do Departamento de Física de acordo com o seu projeto de criação, preferencialmente, será aquele denominado de 'Dedicação Exclusiva', D.E., pois como afirma o professor J. Leite Lopes [28] a "(...) Universidade é, antes e acima de tudo, um grupo de professores (...), integralmente dedicados às suas funções de ensino e pesquisa (...), voltados para elas, por elas absorvidos, vivendo-as em sua vida comum. O trabalho de investigação científica, a pesquisa literária e filosófica, exigem a atenção voltada para os problemas da particular Disciplina em que se trabalha, todas as horas do dia, todos os dias do mês, todos os meses do ano. Sem essa equipe de [professores] devotados a ensinar, criticando fundamentalmente o que os outros descobriram, e a ensinar o que eles próprios são levados a descobrir - como um corolário que decorre da necessidade de se criar para se compreender melhor - sem esta equipe de [professores] assim devotados, não existe Universidade" [28]. Em relação à carga horária em classe, também foi estabelecido que esta deveria ser de oito (08) horas, possibilitando que a aludida plenitude da docência venha a ocorrer.

Para tanto, como estabelecido em [1] é fundamental a existência do Departamento de Física, pois este dará uma
Identidade Acadêmica aos professores de Física, condição básica para ocorrer uma dedicação maior destes, posto que congregará professores de formação acadêmica afim, com pós-graduações nos diversos sub-domínios da Física. Além deste ponto, que a identidade acadêmica certamente propiciará, outros, não menos importantes, serão contemplados com a conseqüente existência da dedicação exclusiva dos professores, dentre eles: o retorno do investimento, feito pela Universidade, nos afastamentos dos professores de Física para a pós-graduação, e o surgimento de grupos de pesquisa bem definidos nos importantes e fundamentais sub-domínios da Física.

\section{A. A Estrutura Acadêmica}

Como estabelecido, a Estrutura Acadêmica do Departamento de Física foi constituída das Sub-Unidades de Ensino, de Pesquisa, de Extensão, e de Apoio Acadêmico, onde cada uma delas congregará as respectivas atividades acadêmicas, desenvolvidas pelo Departamento, dando-lhes o suporte, a organização para que tais atividades se estabeleçam.

\section{A Sub-Unidade de Ensino}

A Atividade de Ensino foi compreendida como o esforço resultante na direção da formação ou modificação da conduta humana, o qual se configura como um processo de duas vias: o Processo Ensino-Aprendizagem, onde os dois atores, o professor e o estudante interagem na busca de seus objetivos. Praticar essa atividade, do ponto de vista do professor, significa conviver com o outro (o estudante), tentar entendê-lo psicológica e socialmente, respeitando as suas virtudes e ajudando a superar as suas lacunas. Na prática de tal atividade o professor pensa, imagina, descobre, cria situações, atinentes ao seu campo do saber, que propiciarão não só o seu planejamento, preparação de aulas, correção de trabalhos e provas, mas, principalmente, propiciarão o bom entendimento das explicações que serão argumentadas em classe ou no atendimento e orientação aos estudantes, no sentido de fazer com que o estudante trabalhe com mão própria, elabore as suas próprias questões, dedique-se ao seu objeto de estudo, tenha objetividade, examine de forma crítica-refletida as situações que se apresentam, busque sempre possibilidades contrárias, seja autocrítico, tenha prudência na afirmação definitiva, verifique sempre os limites e a validade das afirmações, escute as causas, tenha autonomia intelectual, tenha compreensão e colaboração mental para compreender o ponto de vista do outro.

Dessa forma, estabeleceu-se que [1] no processo formativo do estudante estão inerentes o processo de produção do conhecimento (pesquisa) e a relação com a própria sociedade (extensão), articulando-se, portanto, ensinopesquisa-extensão. Sob essas considerações e "em termos de modernidade tecnológica e educativa - e no fundo, na mais bela tradição educativa - professor define-se em primeiríssimo lugar pela capacidade de produção própria de conhecimento. Como decorrência necessária, deve ensinar" [29]. A prática da atividade de ensino, especificamente, será estabelecida através dos papéis da [30]: transmissão 
de conhecimento; disciplinamento da situação pedagógica; avaliação da situação pedagógica; e, vivência de modelos no relacionamento com os estudantes. Não deve haver dicotomia entre pesquisar e ensinar: "quem pesquisa, deve ensinar, quem ensina, só o pode fazer, porque pesquisa" [29]. Conseqüentemente, a atividade de ensino tem o objetivo precípuo de fazer o estudante trabalhar com mão própria, ainda que sob orientação.

Considerando a meta da formação do cidadão para atuar na sociedade (incluindo, nesta, a própria Universidade), classificou-se em dois níveis, com diferentes graus de qualificação o ensino de Física a ser praticado na UEFS:

- O ensino de graduação: porque é fundamental a Universidade ter como papel formar profissionais que atendam às exigências da realidade da sociedade, por exemplo, suprindo a falta de professores de Física da região, e a falta de especialistas para atuar nas indústrias, na área da Física Médica, Física Biológica, Físico-Química, Instrumentação, e outras, e,

- O ensino de pós-graduação: porque é fundamental a Universidade garantir um processo de desenvolvimento sócio-econômico-científico-tecnológico autônomo à sociedade, e isso é atingido na medida em que a formação de diplomados nos Cursos de graduação em Física (Licenciatura e Bacharelado) for melhorada (através da pós-graduação lato sensu) para atender à heterogeneidade das áreas de demanda, no mercado de trabalho, e desenvolvida e aprofundada (através da pós-graduação stricto sensu) para exercer funções científicas.

Como estabelecido anteriormente, a atividade de ensino em Física tem como meta a formação do cidadão consciente e competente, para atuar na sociedade. Consciente da diversidade, da complexidade, da não neutralidade do conhecimento, de que este é produto de (e exprime as) relações que o ser humano estabelece com a natureza na qual se insere, de uma forma geral, e, em particular, consciente de que o conhecimento físico é um dos elementos da base geradora de tal complexidade, e que, juntamente com os conhecimentos dos outros campos do saber, se complementa para formar o pensamento complexo; e, competente na sua especialidade profissional, de tal forma que a ligação entre a teoria e a práxis esteja garantida no campo da Física.

Os cursos de Física, nos seus diferentes graus de qualificação, deverão cumprir este papel. Conseqüentemente, o Departamento de Física deverá oferecer estes cursos nos dois níveis: de graduação, através da Licenciatura e do Bacharelado; e de pós-graduação, através da especialização, do mestrado e do doutorado. Destes, atualmente, somente o curso de licenciatura e de bacharelado estão implantados, e o de especialização, mestrado e doutorado, tiveram as seguintes previsões de implantação: 1999.1, 2001.1 e 2003.1, respectivamente.

O Departamento de Física, além do curso de Física a ele ligado, atende aos seguintes cursos de graduação: Licenciatura em Matemática, Engenharia Civil, Engenharia de Alimentos, Engenharia da Computação e Ciências Biológicas. Com este atendimento, o DFIS presta serviço à Universidade através do oferecimento de disciplinas àqueles cursos, e a outros que sejam implantados, de acordo com as características, objetivos e diferenças existentes entre cada um deles. Portanto, contribuindo para a realização, não só da interdisciplinaridade, mas fundamentalmente da transmeta-disciplinaridade.

\section{Os Laboratórios Didáticos do DFIS}

A Física [1], enquanto ciência natural descreve as leis gerais do Universo. Sua evolução histórico-epistemológica, bem como sua própria natureza, mostram que o método de produção de conhecimento em Física pressupõe uma íntima relação entre teoria e experiência. Isso ilustra que a atividade de laboratório é componente indispensável ao ensino em Física. Entretanto, os roteiros utilizados - invariavelmente dissociados de uma abordagem de ensino adequada - levam os estudantes à postura de meros observadores externos a esta atividade, o que implica em não-entendimento da mesma. Por conta disto, através do projeto de pesquisa "A Problemática do Ensino de Laboratório de Física na UEFS", foi feito, inicialmente, o levantamento desta problemática na UEFS que conduziu a um primeiro diagnóstico de que o ensino de laboratório de Física não está integrado ao ensino de teoria; utiliza roteiros do tipo "receita de bolo" sem suscitar reflexão sobre o experimento; não manifesta um modelo ou abordagem adequada como referencial teórico, entre outros problemas [31-34].

Como um desdobramento daquela pesquisa [1], através do projeto "Estruturação dos Laboratórios Didáticos de Física da UEFS: uma abordagem epistemológica" investigou-se então, uma nova perspectiva para este ensino, buscando uma abordagem com enfoque epistemológico de forma a preparar experimentos e elaborar roteiros que tornem a prática laboratorial uma atividade de investigação para os estudantes, orientando-os a identificar a estrutura do conhecimento, ou seja, sua natureza e como ele é produzido, além de participar efetivamente do experimento, tornando-os ativos no processo ensinoaprendizagem através da interação entre pensar, sentir e fazer, o que os leva a um melhor entendimento dos aspectos conceitual e metodológico de um experimento e, desta forma, à compreensão da interdependência entre teoria e experiência, bem como, em última análise, à superação daqueles problemas já diagnosticados.

Devido a esses estudos sobre os laboratórios didáticos foi estabelecido em [1] a necessidade de implementar a filosofia de ensino de laboratório baseada na abordagem epistemológica. Dessa forma, dando andamento ao projeto de pesquisa "Estruturação dos Laboratórios Didáticos de Física da UEFS: uma abordagem epistemológica", foi assumido que os "Laboratórios Didáticos do Departamento de Física", LAD-FIS devem ser em número de 12, já devidamente contemplados no orçamento aprovado no Planejamento Estratégico da UEFS [25, 35-37], e tais laboratórios deveriam estar situados no "Anexo dos Laboratórios do Módulo IV" [38, 39] cujo orçamento ( $\mathrm{R} \$ 600.000,00$ reais) também já estava contemplado no citado planejamento estratégico. Para ajudar, coordenar, auxiliar o desenvolvimento das atividades de ensino ligadas a tais Laboratórios Didáticos, foi estabelecido que deverá ser constituída a 'Coordenação dos Laboratórios Didáticos do Departamento de Física'. Os Laboratórios Didáticos de acordo com o projeto de criação do DFIS são os que seguem:

- LAD-FIS 01 - Laboratório Didático de Mecânica,

- LAD-FIS 02 - Laboratório Didático de Oscilações e Ondas Mecânicas,

- LAD-FIS 03 - Laboratório Didático de Mecânica dos Meios Contínuos, 
- LAD-FIS 04 - Laboratório Didático de Física Térmica,

- LAD-FIS 05 - Laboratório Didático de Eletricidade e Magnetismo,

- LAD-FIS 06 - Laboratório Didático de Ondas e Radiações Eletromagnéticas,

- LAD-FIS 07 - Laboratório Didático de Instrumentação para o Ensino de Física,

- LAD-FIS 08 - Laboratório Didático de Instrumentação para a Pesquisa em Física,

- LAD-FIS 09 - Laboratório Didático de Eletrônica,

- LAD-FIS 10 - Laboratório Didático de Estrutura da Matéria I,

- LAD-FIS 11 - Laboratório Didático de Estrutura da Matéria II,

- LAD-FIS 12 - Laboratório Didático de Física Aplicada.

\section{A Sub-Unidade de Pesquisa}

A pesquisa em Física, no que tange a sua concepção foi "compreendida como a investigação e o estudo, minudentes e sistemáticos, com o objetivo de descobrir ou estabelecer fatos ou princípios, inéditos ou não, relativos a um sub-domínio qualquer do campo do saber da Física" [1]. Nesse sentido foi assumido que, por um lado, "a pesquisa representa a estratégia própria de produção científica, seja na descoberta de relações reais objetivas, seja na construção de posturas dialéticas que valorizam a história" [29], e por outro, é um "princípio educativo, a partir da questão emancipatória" [29]; a pesquisa, então, foi compreendida como uma "atitude de vida, ou seja, estratégia básica de autoconstrução" [29].

Como uma conseqüência da visão profunda e ao mesmo tempo ampla estabelecida acima, apropriada para uma região que necessita desenvolver-se de forma emancipatória, definiu-se que as pesquisas desenvolvidas pelos docentes do Departamento de Física devem ser concentradas não só em problemas de interesse regional, mas também naqueles de interesse geral. No aspecto regional, as pesquisas realizadas, deverão contribuir para o desenvolvimento técnicocientífico-tecnológico-social da região; no aspecto geral, as pesquisas desenvolvidas deverão contribuir para a Física como um todo, sem fronteiras. Dessa forma, as áreas de pesquisa do Departamento de Física foram pensadas ser coincidentes com os próprios sub-domínios da Física.

Também, em decorrência da concepção acima, indicouse que os grupos de pesquisa deveriam ser divididos nos sub-domínios da Física estabelecidos. De forma a permitir uma universalização, em contrapartida ao isolamento conseqüente da especificidade, indicou-se ademais que a distribuição das atividades de pesquisa nos sub-domínios da Física não impossibilitará a realização de trabalhos de forma supradisciplinar entre os grupos de pesquisa, e entre estes e outros campos do saber, diferentes da Física.

Como diretrizes balizadas por tais considerandos, no projeto de criação do DFIS foram descritas as seguintes ações de caráter geral para que as áreas de pesquisa fossem desenvolvidas plenamente por seus professores:

- Execução do planejamento de capacitação docente dos professores do DFIS ao nível de pós-graduação,

- Implantação na UEFS dos cursos de Física de graduação (bacharelado, 1998.1), e de pósgraduação (especialização, 1999.1, mestrado, 2001.1, e doutorado, 2003.1): pois esses cursos irão contribuir no surgimento/manutenção do Ambiente Acadêmico de discussão e intercâmbio de idéias acerca das disciplinas gerais ou teorias da Física, o que favorecerá, entre outros benefícios, o aparecimento de estudantes para a orientação acadêmica,

- Estruturação do Laboratório de Física Computacional do Departamento de Física, LFC-FIS: porque o crescente avanço da Física em sistemas cada vez mais complexos e de difíceis soluções analíticas faz com que o uso dos computadores se torne mais freqüente. Sendo assim, o Laboratório de Física Computacional, com equipamentos de última geração, será fundamental na busca de soluções dos problemas físicos abordados nos projetos de pesquisa dos professores,

- Estruturação dos Laboratórios Didáticos, LAD-FIS, e do Laboratório de Instrumentação, LIN-FIS: pois como é sabido, a estruturação de laboratórios e a realização de pesquisa experimental em países subdesenvolvidos encontra grandes dificuldades, basicamente porque essas ações requerem decisões políticas do poder público devido aos elevados custos [11]. Nesse sentido, é importante que a UEFS empenhe-se na estruturação dos Laboratórios Didáticos e de Instrumentação posto que os primeiros, além de servirem aos Cursos de Física, prestam-se, juntamente com o segundo, como alavanca para a estruturação dos grandes laboratórios que serão muito importantes para o desenvolvimento da região de Feira de Santana,

- Montagem de uma Biblioteca Setorial de Física: pois o desenvolvimento de qualquer atividade de pesquisa necessita de uma constante atualização do conhecimento.

\section{As Linhas de Pesquisa}

Dando seguimento ao estabelecimento das diretrizes do DFIS, especificamente em relação às primeiras linhas de pesquisa que poderiam ser definidas como uma forma de agregar os docentes na busca da consolidação das atividades de pesquisa do departamento que se propunha criar, estas foram definidas de forma tal a incorporarem as atividades pertinentes e as que estivessem em desenvolvimento na época, indicando apropriadamente que outras linhas poderiam ser definidas com o esperado desenvolvimento do Departamento de Física. As primeiras linhas de pesquisa de caráter mais amplo e agregador foram as seguintes:

- Teoria de Campos,

- Óptica,

- Estrutura e Propriedades dos Líquidos e Sólidos,

- Magnetismo, 
- Espalhamento,

- Astronomia,

- Instrumentação em Física,

- Ensino de Física,

- História e Filosofia da Física,

- Física Biológica,

- Física das Fontes não Convencionais de Energia.

Importante frisar que, nessa diretriz, está implícito o fato de que o DFIS deveria como decorrência imediata da agregação inicial dos docentes, estabelecer os primeiros grupos de pesquisa (que incorporariam as respectivas linhas de pesquisa acima estabelecidas, bem como definiria outras), de acordo com os sub-domínios da Física estabelecidos.

\section{Os Laboratórios de Pesquisa do DFIS}

No que tange aos laboratórios de pesquisa, um pressuposto importante foi assumido [1]. Como estabelecido anteriormente, a Física, enquanto ciência natural descreve as leis gerais do Universo. Sua natureza mostra que o método de produção de conhecimento pressupõe uma íntima relação entre teoria e experiência. Isso ilustra decisivamente, que a atividade de laboratório é um componente indispensável para a atividade de pesquisa em Física. Desta forma, a partir desse pressuposto, considerou-se que a existência de Laboratórios de Pesquisa, em uma instituição, é condição sine qua non para o desenvolvimento de pesquisa competitiva em Física, seja ela teórica ou experimental.

Como conseqüência do PCAD-FIS, $3^{\mathrm{a}}$ ed. [23], e levando em conta a consideração do parágrafo anterior, foi planejada a estruturação dos Laboratórios de Pesquisa em Física, ficando os seus projetos a serem elaborados a partir das características delineadas em [1], inclusive com parte de seus orçamentos (aquelas relacionadas com o espaço físico) devidamente contempladas no Planejamento Estratégico da UEFS [25, 35-37]. Em sua maioria deveriam ficar instalados no Módulo Prático, do Módulo IV, e o restante no "Anexo dos Laboratórios do Módulo IV" [38]. Inicialmente foi previsto ser em número de 10:

- LOP-FIS - Laboratório de Óptica,

- LFA-FIS - Laboratório de Fotoacústica,

- LMO-FIS - Laboratório de Magnéto-Óptica,

- LEE-FIS - Laboratório de Espalhamento Eletromagnético,

- LAF-FIS - Laboratório de Astronomia Fundamental,

- LAO-FIS - Laboratório de Astrofísica Observacional,

- LIN-FIS - Laboratório de Instrumentação,

- LFC-FIS - Laboratório de Física Computacional,

- LFB-FIS - Laboratório de Física Biológica,

- LEA-FIS - Laboratório de Energia Alternativa.

\section{A Sub-Unidade de Extensão}

Nas considerações sobre a atividade de extensão foram feitos amplos estudos [40-43] visando a sua compreensão nos seus mais variados aspectos. Dentre as diretrizes gerais sobre a concepção e prática de tal atividade que foram delineadas, pode-se citar:

- Desenvolver ações supradisciplinares através de projetos de extensão temáticos, na busca de soluções de problemas da realidade que exigem a participação de representantes altamente qualificados de cada uma das disciplinas envolvidas,

- Disseminar no interior da Universidade a prática humanista através de projetos de extensão culturais que têm, por um lado, o objetivo de conscientizar a comunidade universitária sobre a realidade, sobre o pensamento, sobre a prática da vida, sobre a função de cada membro da comunidade acadêmica, e por outro, de fazer da Universidade um local de vida agradável. Tais projetos deveriam caracterizar-se pela busca da estética, enquanto desejo, de tal forma que aglutinariam profissionais de outras Disciplinas interessados em adquirir aqueles conhecimentos como uma manifestação cultural da busca da liberdade de cada um,

- Disseminar na sociedade ações que tenham como objetivo propiciar a criação de uma consciência crítica de seus problemas, tanto do ponto de vista nacional, como regional e local, contribuindo, portanto, para o estabelecimento da cultura nacional, i.e., da formação da opinião pública, e,

- Participar de programas permanentes de extensão, desenvolvidos pela Universidade, que tenham por objetivo integrar a Universidade com os setores tradicionalmente marginalizados do conhecimento acadêmico.

No que tange ao aspecto da natureza da extensão, a extensão em Física foi compreendida como "o conjunto de atos praticados pelo Departamento de Física no sentido de integrar-se à sociedade, atendendo as finalidades básicas do compromisso político-social e da prática acadêmica. A primeira, referindo-se a obrigação da Universidade reverter seus benefícios em favor da maioria da população, sem perda da pluralidade, que é essencial à prática universitária, e sem confundir definição filosófica-política com postura política-partidária; a segunda, referindo-se à extensão como o elemento articulador do ensino e da pesquisa com a sociedade, outorgando à Universidade uma função transformadora do meio social" [1]. A Extensão, portanto, foi pensada ser "uma via de mão dupla, com trânsito assegurado à comunidade acadêmica que encontrará, na sociedade, a oportunidade da elaboração da práxis de um conhecimento acadêmico; no retorno à Universidade, docentes e discentes trarão um aprendizado que, submetido à reflexão teórica, será acrescido àquele conhecimento" [40]. Dessa forma, as áreas de extensão do Departamento de Física foram pensadas, também, ser coincidentes com os próprios subdomínios da Física.

No aspecto das definições dos atos extensionistas praticados pelo Departamento de Física tem-se [1]: 
(i) Difusão Científica: é compreendida como a ação em que a Universidade, em particular o Departamento de Física, é tomado como um pólo de onde emanam e circulam os produtos culturais e científicos por ele criados. Entre outras atividades, nesse ato se incluem: os eventos promovidos pelo Departamento de Física, tais como 'Semana de Física', e as participações dos professores do DFIS naqueles promovidos por outras Instituições, tais como 'Reunião Anual da SBPC', 'Encontro de Físicos do Norte/Nordeste'; as publicações especializadas e de divulgação editadas pelo Departamento de Física, e as participações dos professores do DFIS naquelas editadas por outras Instituições; o registro de marcas e patentes; os cursos e outras formas de apresentação de divulgação, tais como cursos, exposição de filmes, palestras, colóquios, seminários, mesas-redondas, ou outros trabalhos equivalentes cuja natureza seja a de divulgação; outros;

(ii) Ação Cultural: é compreendida como a ação em que a Universidade, em particular o Departamento de Física, estabelece uma relação com a comunidade, tanto externa quanto interna, na qual ambos (o Departamento e a comunidade) comportam-se ativamente como sujeitos objetivando a sensibilização e conscientização junto às comunidades na valorização e proteção do Patrimônio histórico, artístico, científico e cultural, a formação crítica da opinião pública, e a prática humanística;

(iii) Aperfeiçoamento Profissional-Acadêmico da população, através de Cursos: é compreendido como a ação em que a Universidade, em particular o Departamento de Física, desenvolve a educação continuada com o objetivo de evitar que o perfil dos profissionais formados em Física torne-se obsoleto no decurso da vida por conta da dinâmica existente no processo de produção científica e tecnológica desse campo do saber;

(iv) Assessoria-Consultoria Técnica, Científica e Pedagógica: é compreendido como a ação em que a Universidade, em particular o Departamento de Física, desenvolve a prestação de serviços com o objetivo de auxiliar a comunidade nas suas formas de organização através de atividades de assessorias e (ou) consultorias no campo da Física;

(v) Trabalhos Técnico-Científicos apresentados pelo Departamento de Física à comunidade em geral, seja ela interna ou externa à Universidade: é compreendido como a ação em que a Universidade, em particular o Departamento de Física, dissemina o conhecimento físico de natureza específica através de atividades do tipo: seminários, colóquios, conferências, dentre outras; e,

(vi) Trabalhos Técnico-Científicos apresentados por Instituições públicas ou privadas ao Departamento de Física e à comunidade em geral, seja ele interna ou externa à Universidade: é compreendido como a ação em que a Universidade, em particular o Departamento de Física, recebe o conhecimento físico emanado de outras Instituições de natureza específica através de atividades do tipo: seminários, colóquios, conferências, e semelhantes.
Em decorrência das definições e concepções estabelecidas, indicou-se que os grupos de extensão que desenvolverão os atos extensionistas, deveriam ser divididos nos subdomínios da Física, estabelecidos.

Para garantir a universalização, em contrapartida ao isolamento conseqüente da especificidade, indicou-se também que a distribuição das atividades de extensão nos subdomínios da Física não impossibilitará a realização de trabalhos de forma supradisciplinar entre os grupos de extensão, e entre estes e outras áreas do saber, diferentes da Física.

As diretrizes advindas de tais aspectos abordados no estudo da atividade de extensão estabeleceram as seguintes ações de caráter geral para que as áreas de extensão fossem desenvolvidas plenamente pelos professores do DFIS:

- "Execução do planejamento de capacitação docente dos professores do DFIS ao nível de pós-graduação,

- Implantação na UEFS dos cursos de Física de graduação (bacharelado, 1998.1), e de pósgraduação (especialização, 1999.1, mestrado, 2001.1, e doutorado, 2003.1): pois, sendo a extensão a articuladora das atividades de ensino e de pesquisa com a sociedade, para que os seus objetivos sejam alcançados, devem existir primordialmente no Departamento de Física as atividades de ensino e de pesquisa, o que permitirá ao DFIS reverter, para a maioria da população, os benefícios advindos do conhecimento físico; a extensão em Física só terá sentido se existirem as atividades de ensino e de pesquisa, e os cursos de Física fornecerão as condições básicas para que estas atividades existam e sejam articuladas pela primeira, na integração com a sociedade,

- Montagem de uma Biblioteca Setorial de Física: pois a elaboração e o próprio desenvolvimento de qualquer atividade de extensão não dispensam uma pesquisa bibliográfica" [1],

- Estruturação do Laboratório de Ensino de Física LEF-FIS de acordo com PCAD-FIS $3^{\mathrm{a}}$ ed. [23]: visando atender inicialmente docentes do primeiro grau da rede pública da região de Feira de Santana com o objetivo de praticar os atos extensionistas 'Assessoria técnica-científica e pedagógica' e 'Aperfeiçoamento profissional-acadêmico', devendo tal laboratório localizar-se no Módulo Prático do Módulo IV [1].

As atividades de extensão, de caráter geral, que estavam em desenvolvimento e as que foram propostas são as que seguem:

- Interações Extensionistas em Física: atividade do tipo "Trabalhos Técnico-Científicos apresentados por Instituições públicas ou privadas ao Departamento de Física e à comunidade em geral, seja ele interna ou externa à Universidade" que na época constava de seminários seguidos de discussões, proferidos por professores de outras instituições convidados, objetivando o aprofundamento das questões abordadas para o desenvolvimento e fortalecimento das áreas de pesquisa e extensão,

- Difusão de Física no $1^{\circ}$ e $2^{\mathbf{o}}$ graus: atividade do tipo "Difusão Científica" que na época constava de 
palestras e exposições de filmes e experiências feitas na UEFS e nas escolas do $1^{\circ}$ e $2^{\circ}$ graus, objetivando divulgar e propagar a Física nas escolas de $1^{\circ}$ e $2^{\circ}$ graus para mostrar não só os aspectos fenomenológicos e experimentais, mas também a vasta possibilidade de utilização de seus conhecimentos. Com isso almejava-se evitar a grande aversão que existe em relação à Física, atrair futuros interessados nos cursos de Física, bem como evitar a evasão existente nesses cursos,

- Curso de Aperfeiçoamento para Professores de Física do $2^{\circ}$ grau: atividade do tipo "Aperfeiçoamento Profissional-Acadêmico da população através de Cursos" que visava suprir a carência de conteúdo de Física dos professores do $2^{\circ}$ grau,

- Caderno de Física da UEFS: atividade do tipo "Difusão Científica, na forma de Divulgação" que visava divulgar, na forma de artigos, resultados de extensão, pesquisa e experiências em ensino, importantes para o conhecimento em Física, em linguagem ao nível de graduação, com periodicidade semestral. Além disso, a capa do caderno tinha como objetivo a divulgação das artes,

- Pre-Prints de Física ou Notas de Física: atividade do tipo "Difusão Científica, na forma de Publicação Especializada" que visava divulgar resultados de pesquisa em uma linguagem ao nível de pósgraduação, com cada número contendo um só trabalho,

- Colóquios de Física: atividade do tipo "Trabalhos Técnico-Científicos apresentados por Instituições públicas ou privadas ao Departamento de Física e à comunidade em geral, seja ele interna ou externa à Universidade" de caráter mais abrangente no que se refere à abordagem ao campo do saber da Física, que visava propiciar e estimular o surgimento de ações supradisciplinares relacionadas com a Física,

- Seminários de Física: atividades do tipo "Trabalhos Técnico-Científicos apresentados pelo Departamento de Física à comunidade em geral, seja ele interna ou externa à Universidade" e do tipo "Trabalhos Técnico-Científicos apresentados por Instituições públicas ou privadas ao Departamento de Física e à comunidade em geral, seja ele interna ou externa à Universidade", ambas de caráter mais específico no que se refere à abordagem ao campo do saber da Física, que visavam propiciar e estimular as discussões possibilitando não só o surgimento de pesquisas relacionadas ao tema exposto, mas também o fortalecimento das pesquisas em andamento,

- Semana de Física: atividade do tipo "Difusão Científica na forma de Evento", constando de minicursos, palestras, sessão de comunicações, e mesasredondas que visavam integrar o DFIS com a comunidade universitária, bem como com a comunidade da região de Feira de Santana, com periodicidade anual. Além disso, para divulgar os trabalhos do evento, deveriam ser publicados os "Anais da Semana de Física da UEFS", e,

- Escola de Verão do Departamento de Física: atividade do tipo "Difusão Científica na forma de
Evento" e do tipo "Aperfeiçoamento ProfissionalAcadêmico da população através de Cursos" que visava apresentar temas importantes para a complementação ou especialização da formação dos estudantes de graduação em Física, Matemática, Química, Engenharia, Biologia, Geografia, Geologia, História, Filosofia e áreas correlatas, bem como de profissionais e graduados ao nível de pós-graduação e com periodicidade anual.

\section{A Sub-Unidade de Apoio Acadêmico}

Nesse ponto aparece uma grande inovação na proposta de criação do DFIS: a definição da atividade de apoio acadêmico. Para compreender a sua profundidade e alcance, resgatemos os diferentes aspectos abordados em [1] sobre ela.

Em relação ao seu conceito e natureza, a Atividade de Apoio Acadêmico foi compreendida como o conjunto de ações que visam estimular a criação de grupos de pesquisa e extensão, $e$ de interdependências e ajudas mútuas entre os professores e entre os grupos de pesquisa e extensão existentes, e que visam propiciar o bom andamento das atividades docentes e dos diversos Laboratórios Acadêmicos de Física. A meta prioritária da Atividade de Apoio Acadêmico foi estabelecida como a busca do desenvolvimento equilibrado, harmônico e homogêneo do DFIS, o que em última análise, segundo o projeto de criação do DFIS, garantirá a identidade acadêmica dos professores, condição básica para o surgimento da personalidade e ambiente acadêmico de tal departamento.

Dessa forma, as atividades de apoio acadêmico podem ser divididas em três classes distintas, por conta de seus objetos de ação; são elas:

- Atividade de estímulo à criação de grupos de pesquisa e extensão,

- Atividade de estímulo à criação de interdependências e ajudas mútuas,

- Atividade de propiciação do bom andamento das atividades docentes e dos laboratórios didáticos.

No que tange aos objetivos específicos de cada uma das classes de atividades, tem-se o que segue.

O estímulo à criação de grupos de pesquisa e extensão tem como objetivo buscar a consolidação do Departamento de Física no cenário nacional.

O estímulo à criação de interdependências e ajudas mútuas entre os professores e entre os grupos de pesquisa e extensão existentes tem como objetivo possibilitar que as debilidades que uns apresentam sejam superadas pela ajuda dos outros, o que permitirá que os menos avançados encontrem condições favoráveis para ascender ao nível dos mais avançados.

A propiciação do bom andamento das atividades docentes e dos laboratórios acadêmicos tem como objetivo possibilitar a viabilização da existência de material bibliográfico; da manutenção dos equipamentos, do desenvolvimento de peças de reposição e de amostras diversas; bem como da existência de apoio técnico em áreas específicas através do Setor de Apoio do Departamento de Física.

Desnecessário ressaltar quão importante para o DFIS deve ser a estruturação das atividades de apoio acadêmico. 
Questões como equilíbrio, harmonia, identidade, personalidade e ambiente acadêmico, bem como condições de trabalho, são muito caras e objeto de desejo em toda e qualquer instituição acadêmica que lide com o ser humano. A proposta inovadora da existência da Sub-Unidade de Apoio Acadêmico vai nessa direção e sem dúvida é uma grande contribuição que a UEFS pode dar na discussão, sempre profícua, do significado de Universidade.

\section{O Setor de Apoio do DFIS}

Como uma forma de articular as ações pertencentes à atividade de propiciação do bom andamento das atividades docentes e dos laboratórios acadêmicos, foi proposta a criação do Setor de Apoio do DFIS, SETAP-FIS. Como é bastante conhecido, o bom andamento das atividades docentes, e dos diversos Laboratórios Acadêmicos de Física pressupõe a existência de material bibliográfico, a manutenção dos equipamentos, o desenvolvimento de peças de reposição e de amostras diversas, bem como a existência de apoio técnico em áreas específicas (química, criogenia, dentre outras), dessa forma, para organizar sistematicamente o conjunto de tais ações, a estruturação do SETAPFIS é fundamental e deve ocorrer, segundo a diretriz apontada em [1]: na forma de Biblioteca Setorial do Departamento de Física, na forma de Oficinas de eletrônica, de eletricidade, de mecânica, de vidros, de carpintaria e outras, e na forma de Laboratórios de manipulação de produtos químicos, de criogenia, dentre outros, com técnicos qualificados para atender as necessidades que advirão com o desenvolvimento das atividades acadêmicas nos laboratórios do Departamento de Física. Cada uma de tais formas será considerada uma das divisões do SETAP-FIS.

Para ajudar, coordenar, auxiliar o desenvolvimento das atividades pertinentes ao Setor de Apoio do Departamento de Física, deve ser constituída a 'Coordenação do Setor de Apoio do Departamento de Física'.

\section{A Biblioteca Setorial do DFIS}

A Biblioteca Setorial do Departamento de Física destinase ao apoio acadêmico das atividades docentes dos professores, bem como dos Estudantes, no que concerne ao campo do saber da Física, visando oferecer todo o tipo de acervo bibliográfico pertinente e sua apropriada manutenção. Para a sua coordenação será constituída a 'Coordenação da Biblioteca Setorial do Departamento de Física'.

\section{Os Laboratórios de Apoio do DFIS}

Os Laboratórios de Apoio do Departamento de Física destinam-se ao apoio técnico em áreas específicas tais como criogenia, química, dentre outras que auxiliarão o desenvolvimento das atividades docentes, bem como as atividades do próprio dia a dia dos Laboratórios Acadêmicos do Departamento de Física.

\section{As Oficinas de Apoio do DFIS}

As Oficinas de Apoio do Departamento de Física destinam-se à manutenção técnica dos equipamentos, ao desenvolvimento de peças de reposição e de amostras diversas, que auxiliarão o andamento das atividades docentes, bem como auxiliarão as atividades do próprio dia a dia dos
Laboratórios Acadêmicos do Departamento de Física. Entre tais Oficinas de Apoio, para o início dos trabalhos do DFIS foi proposta como diretriz a estruturação das Oficinas de Eletrônica, de Eletricidade, de Mecânica, de Vidros, de Carpintaria, dentre outras.

\section{B. A Estrutura Administrativa}

A questão relacionada à estrutura administrativa é um ponto sempre delicado de estudo e análise devido à sua estrita vinculação com o poder na universidade ou em qualquer instituição, como pode ser visto no texto de Meirelles [44]. O estudo da natureza, concepção e diretrizes das atividades administrativas, a serem desenvolvidas no DFIS, teve como premissa básica não só a busca por uma organização ágil, eficiente e de qualidade, mas que fosse pautada na ética, idoneidade, no respeito à decisão da maioria sem desrespeitar a minoria, na serenidade, na transparência e na pluralidade. Além disso, um ponto analisado foi aquele relacionado com o papel personalista e centralizador da figura do diretor de um departamento, cuja alternativa proposta, explicitada na organização da estrutura administrativa do DFIS em seis coordenações (vide Figura 2), foi uma solução encontrada.

Frise-se, ainda, que o estudo da estrutura administrativa se pautou em reafirmar os princípios fundamentais que regem uma boa administração pública, os quais foram consubstanciados no projeto do DFIS como segue:

- Planejamento - quando foram estabelecidas as diretrizes e metas que deverão orientar a ação administrativa do DFIS através de um plano geral administrativo, pautado nas ações relativas à estrutura acadêmica,

- Coordenação - quando foi proposto um agente harmonizador das atividades administrativas, as seis coordenações administrativas, submetendo-as, portanto, ao que foi planejado e evitando dispersão de esforços e divergências de soluções,

- Descentralização - quando também foram propostas as seis coordenações, além das diversas comissões a elas associadas, diluindo conseqüentemente as decisões e permitindo a participação de todos os agentes, os professores, na implementação das ações administrativas,

- Delegação de competências - quando foi estabelecida a importância da participação do conjunto de professores do DFIS (não necessariamente aqueles investidos nos cargos das coordenações) apreciando processos, representando o departamento em órgãos colegiados da universidade, participando de comissões, de bancas examinadoras, assegurando assim uma maior rapidez e objetividade das decisões, e,

- Acompanhamento - quando foi estabelecido que através das coordenações e comissões exercitar-seá, de forma democrática e serena, a fiscalizaçãoacompanhamento do cumprimento da lei e das normas, bem como das atividades docentes, no sentido da educação e orientação dos agentes, os professores.

Como estabelecido mais acima, a Estrutura Administrativa do Departamento de Física da UEFS foi constituída das seguintes coordenações: Conselho Departamental, 
Coordenação Geral, Coordenação de Ensino, Coordenação de Pesquisa, Coordenação de Extensão, e Coordenação de Apoio Acadêmico. Cada uma delas congregando as atividades administrativas respectivas a serem desenvolvidas pelo Departamento e como não poderia deixar de ser, constituintes de uma estrutura decorrente da natureza da Estrutura Acadêmica e da própria concepção do Departamento de Física assumidas. Para uma perfeita compreensão da magnitude dos elementos constituintes da estrutura administrativa será a seguir descrito cada um daqueles elementos a ela pertencentes de acordo com o estabelecido em [1].

Em termos de concepção e respeitando a premissa básica acima aludida, bem como os princípios fundamentais da boa administração, a atividade administrativa foi considerada como aquela que auxiliará o desenvolvimento das atividades de ensino, pesquisa e extensão, como um meio coordenador destas atividades acadêmicas. Sendo assim, o conjunto de seus atos deverá ser praticado no sentido de viabilizar a plenitude do exercício destas atividades acadêmicas.

No aspecto da participação dos docentes do DFIS nas atividades administrativas, estas foram sistematizadas por meio do exercício dos seguintes atos:

I. Comparecimento às reuniões dos órgãos colegiados:

- Conselho Departamental do Departamento de Física,

- Coordenações de Ensino, Pesquisa, Extensão, e de Apoio Acadêmico,

- Colegiados dos Cursos ligados ao Departamento de Física,

- Colegiados dos Cursos atendidos pelo Departamento de Física,

- Órgãos colegiados, nos quais houver representação do Departamento de Física;

II. Apreciação de processos, com elaboração de parecer;

III. Participação em comissões;

IV. Participação em bancas examinadoras;

V. Representação de classe no CONSU;

VI. Representação nos Órgãos Superiores da Universidade;

VII. Representação nos colegiados dos Cursos ligados ao Departamento de Física;

VIII. Representação nos colegiados dos Cursos atendidos pelo Departamento de Física;

IX. Coordenação de atividades de pesquisa e extensão;

X. Coordenação e vice-coordenação dos colegiados ligados ao DFIS;

XI. Direção e vice-direção do DFIS;

XII. Coordenação das Coordenações de Ensino, de Pesquisa, de Extensão, e de Apoio Acadêmico; e,

XIII. Participação em outros cargos da administração.
Esse estudo acerca das atividades administrativas revela a complexidade de seus atos e a importância da existência de uma estrutura administrativa para que o principal objetivo, o de coordenar as atividades de ensino, pesquisa $e$ extensão, seja alcançado. No campo do saber da Física, as diretrizes traçadas, conseqüentes do estudo citado, estabeleceram as seguintes ações:

- Criação do Departamento de Física da UEFS;

- Efetivação de um(a) secretário(a) exclusivo(a) do Departamento de Física para fazer o seu expediente, pois a quantidade desses trabalhos de secretariado ou de expediente é muito grande;

- Efetivação de funcionários técnico-administrativos com formação em Direito, Administração e Contabilidade para, em suas respectivas especialidades, darem o suporte para o bom andamento administrativo do Departamento de Física;

- Instalação de um telefone e um fax em razão da necessidade de contatos com os colaboradores do Departamento de Física, localizados em outras instituições, de maior agilidade no intercâmbio de informações (artigos, ensaios, pre-prints, não disponíveis na biblioteca da UEFS e indispensáveis ao andamento das pesquisas), bem como de pesquisa de fornecedores, cotação de equipamentos e materiais de laboratório, dentre outros;

- Estabelecimento de um espaço físico para sediar o Departamento de Física: com isso o mesmo poderá alocar apropriadamente os equipamentos acima mencionados, bem como arquivos, armários, mesas, a secretária, o diretor, para o seu pleno andamento administrativo;

- Instalação de gabinetes para todos os professores do Departamento de Física, com área de produção e de convivência para que as atividades de ensino, pesquisa e extensão possam ser plenamente alcançadas. É fundamental que cada professor do Departamento tenha o seu gabinete, o que propiciará a tranqüilidade necessária para o cumprimento pleno da docência.

\section{O Conselho Departamental}

O Conselho Departamental foi definido como o órgão máximo de deliberação e coordenação do Departamento de Física da UEFS. Dentre outras atribuições ele será o responsável pela adoção e implementação das políticas de produção e transmissão do conhecimento científico de Física, numa perspectiva extensionista de alcance social, o que outorgará à Universidade, neste campo do saber, uma função transformadora da sociedade. Será constituído de: Diretor do Departamento; docentes integrantes da carreira do magistério superior, com exercício no DFIS e Representantes discentes. Tais representações discentes são escolhidas de acordo com o Regimento Geral da Universidade. As deliberações aprovadas nas coordenações de ensino, pesquisa, extensão e de apoio acadêmico de acordo com [1], devem ser encaminhadas à Coordenação Geral que as submeterá à apreciação do Conselho Departamental. 
Com isso, os cinco princípios que regem uma boa administração pública, de uma forma geral, poderiam ser estabelecidos; particularmente, o conjunto dos professores poderia elaborar o plano geral administrativo de acordo com as diretrizes e metas relativas à estrutura acadêmica adotada para o DFIS.

\section{A Coordenação Geral}

A Coordenação Geral foi definida como o órgão de coordenação, execução e acompanhamento das atividades do Departamento de Física da UEFS. Será constituída de: Diretor do Departamento, Vice-Diretor, Coordenador de Ensino, Coordenador de Pesquisa, Coordenador de Extensão e, Coordenador de Apoio Acadêmico. Dessa forma, a implantação da Coordenação Geral terá como um de seus grandes objetivos propiciar que os princípios de coordenação, descentralização e acompanhamento da boa administração possam ser satisfeitos.

\section{A Coordenação de Ensino}

A Coordenação de Ensino foi definida como o órgão que representará a Sub-Unidade de Ensino do Departamento de Física. Será, portanto, o órgão que coordenará e auxiliará o desenvolvimento das Atividades de Ensino, através das Atividades Administrativas pertinentes. Será constituída de: Coordenador de Ensino, Representantes das Matérias nos Colegiados de Cursos ligados (atendidos) ao (pelo) DFIS, Coordenadores de disciplinas curriculares com mais de uma turma, Coordenador de Atendimento e Orientação a Estudantes, Coordenador dos Laboratórios Didáticos e Coordenador da Biblioteca. Dessa forma, pela sua constituição, percebe-se que um dos papeis a ser desenvolvido pela Coordenação de Ensino é o de propiciar um efetivo relacionamento com os colegiados dos cursos atendidos pelo departamento, contribuindo para que o diálogo entre o departamento e os colegiados possa fluir de maneira efetiva e equilibrada. Além disso, ter-se-ia um elemento administrativo apropriado para implementar as diretrizes e metas atinentes à Sub-Unidade de Ensino.

\section{A Coordenação de Pesquisa}

A Coordenação de Pesquisa foi definida como o órgão que representará a Sub-Unidade de Pesquisa do Departamento de Física. Será, portanto, o órgão que coordenará e auxiliará o desenvolvimento das Atividades de Pesquisa, através das Atividades Administrativas pertinentes. Será constituída de: Coordenador de Pesquisa, Coordenadores dos Laboratórios de Pesquisa, Coordenadores dos Grupos de Pesquisa, Responsáveis pelas respectivas Linhas de Pesquisa (estariam presentes enquanto tal linha de pesquisa não fosse incorporada a algum grupo de pesquisa). A partir dessa constituição a Coordenação de Pesquisa poderá implementar as diretrizes e metas atinentes à Sub-Unidade de Pesquisa, além de criar condições para que os grupos de pesquisa sejam formados, as linhas de pesquisa definidas e os laboratórios de pesquisa sejam estruturados.

\section{A Coordenação de Extensão}

A Coordenação de Extensão foi definida como o órgão que representará a Sub-Unidade de Extensão do Departamento de Física. Será, portanto, o órgão que coordenará e auxiliará o desenvolvimento das Atividades de Extensão, através das Atividades Administrativas pertinentes. Será constituída de: Coordenador de Extensão, Coordenador do Curso de Aperfeiçoamento para Professores de Física do $2^{\circ}$ grau, Coordenador do projeto 'Interações Extensionistas em Física', Coordenador do projeto 'Difusão de Física no $1^{\circ}$ e $2^{\circ}$ graus', Editor do 'Caderno de Física da UEFS', Editor dos 'Pre-Prints de Física', Coordenador dos 'Colóquios de Física', Coordenador dos 'Seminários de Física', Coordenador da 'Semana de Física da UEFS', Coordenador da 'Escola de Verão do Departamento de Física', Coordenadores dos Laboratórios de Extensão, Coordenadores dos Grupos de Extensão. A Coordenação de Extensão, portanto, tem o objetivo precípuo de implementar as diretrizes e metas advindas da Sub-Unidade de Extensão, além de criar as condições para que os projetos bem como os grupos de extensão sejam formados e tenham continuidade.

\section{A Coordenação de Apoio Acadêmico}

A Coordenação de Apoio Acadêmico foi definida como o órgão que representará a Sub-Unidade de Apoio Acadêmico do Departamento de Física. Será, portanto, o órgão que coordenará e auxiliará o desenvolvimento das Atividades de Apoio Acadêmico, através das Atividades Administrativas pertinentes. Será constituída de: Coordenador de Apoio Acadêmico, representante da Coordenação de Ensino, representante da Coordenação de Pesquisa, representante da Coordenação de Extensão, e Coordenador do Setor de Apoio do Departamento de Física. Nesse sentido, o papel da Coordenação de Apoio Acadêmico será de fundamental importância na medida em que tal coordenação atuará como que formando uma cola que garantirá a unidade do DFIS, visando a implementação do equilíbrio, da harmonia, da identidade e personalidade acadêmicas, bem como de condições de trabalho.

\section{Previsão de Carga Horária Docente no Decênio 1998-2007}

Um ponto importante considerado no projeto de criação do departamento foi aquele relacionado com a carga horária docente, bem como com a contratação de professores. Com o objetivo de atender aos requisitos da generalidade, permanência e eficiência, no que tange ao serviço público a ser prestado pelo departamento, estabeleceu-se uma previsão de carga horária docente (denotada na Tabela II (anexo) por 'Carga Horária Docente total, por semana') para um intervalo de 10 anos, levando em conta a saída para qualificação dos docentes assim como a contratação de profissionais com a mais alta qualificação.

Para estabelecer a programação em apreço foram levadas em conta somente as disciplinas dos cursos atendidos pela então Área de Física que na época existiam (Matemática, Biologia e Engenharia Civil) e aquelas do 
curso de Física recém implantado (denotadas na Tabela II por 'Carga Horária em Sala de Aula, por semana'). Para contemplar as atividades de ensino (aquelas outras que se complementam com as da sala de aula), de pesquisa, de extensão e administrativa do docente, considerou-se a carga horária docente de oito horas em sala de aula. Dessa forma, a previsão proposta não contemplava a existência dos cargos administrativos de Coordenador de Colegiado e de Diretor do Departamento, nem o surgimento de novos cursos e no aspecto das atividades de pesquisa e extensão, não contemplava o seu aumento efetivo de acordo com as diretrizes e perspectivas do próprio projeto. Em outras palavras, essa previsão de carga horária docente foi a mínima possível para o departamento conseguir ser implementado e deveria ser reavaliada oportunamente para contemplar os possíveis avanços advindos das diretrizes e perspectivas estabelecidas no projeto. Amparado nessas considerações, a previsão de carga horária docente no decênio 1998-2007 foi estabelecida de acordo com a Tabela II (anexo).

Uma outra perspectiva estabelecida no projeto de criação do DFIS, relacionada com a previsão de contratação de professores doutores, de acordo com a Tabela II, foi a de contribuir para a diminuição do déficit da massa crítica de doutores no campo do saber da Física no país e, em particular, no estado da Bahia, especificamente na região do semiárido baiano. Frise-se que essa perspectiva também objetiva atender aos requisitos da generalidade, permanência e eficiência do serviço público prestado pelo departamento. Essa massa crítica, segundo alguns critérios de análise, é representada pela relação entre o número de doutores nas ciências físicas e o produto interno bruto, (PIB), de uma nação, tomando como base os países desenvolvidos.

Para estabelecer tal critério, foram considerados os estudos realizados pela SBF [11] sobre estas questões no ano de 1994, por ocasião do importante trabalho a respeito da Física no Brasil. Neste trabalho ficou estabelecido que, para cada US\$ 160 bilhões do PIB devem existir aproximadamente 1000 físicos. Tendo em conta a nova relação cambial que se colocou com a implantação do Plano Real em junho de 1996 e para contemplar o natural aumento que o país sempre apresenta, relativo ao seu PIB, considerou-se como fator de referência atualizado que para cada $\mathrm{R} \$ 160$ bilhões do PIB brasileiro correspondam 1000 físicos.

De acordo com os dados obtidos em [1], relativos ao ano de 1996, o número de doutores no campo do saber da Física no estado da Bahia deveria ser de 214; considerando a região do semi-árido baiano como um dos importantes pólos de desenvolvimento do estado e estipulando para ela um percentual de $20 \%$ desse total, tal região deveria ter, no ano de 1996, 42 doutores no campo do saber da Física.

Evidentemente, esse critério é muito limitado, pois o PIB brasileiro é muito pequeno para as reais necessidades da população do país, particularmente para a população do semi-árido baiano. No entanto, ainda que simplificado e recorrendo a um critério bastante limitado, esse estudo, como já aludido, mostra que o número de doutores no campo do saber da Física da região de Feira de Santana é insuficiente posto que, na época da elaboração do projeto de criação do Departamento de Física (1998), a então Área de Física só tinha em seu quadro de docentes 05 doutores. Dessa forma, a perspectiva estabelecida no projeto de criação, como pode ser visto no gráfico abaixo, era de que a existência do Departamento de Física da UEFS, decisivamente, contribuiria para atenuar esse déficit [1]. Cabe frisar que o número de doutores que a região do semi-árido baiano deveria ter no ano de 2003, baseado na sua participação no PIB total do estado naquele ano $(\sim \mathrm{R} \$ 75$ bilhões) seria de 94 doutores, o que mostra quão distante está o número atual de doutores no DFIS do número estimado como necessário e mesmo daquele estimado em 1997 por ocasião do projeto do DFIS [1].

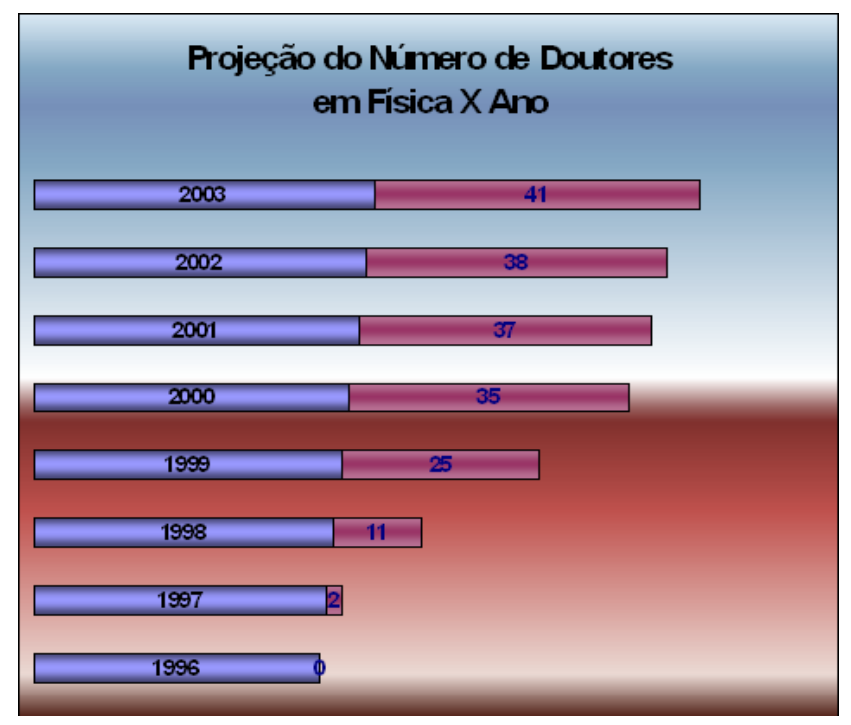

Fig. 3: Projeção do Número de Doutores em Física $\times$ Ano

\section{COMENTÁRIOS ATUAIS SOBRE A EVOLUÇÃO DO DFIS CONSIDERANDO AS DIRETRIZES E PERSPECTIVAS DELINEADAS EM SEU PROJETO}

Antes de estabelecermos comentários atuais sobre a evolução do DFIS levando em conta a ótica das considerações teórico-filosóficas consubstanciadas no seu projeto de criação, realcemos o fato de que no cerne das discussões a cerca das diretrizes e perspectivas estabelecidas em tal projeto, estava a preocupação em atender os requisitos do serviço público prestado pelo departamento. De forma explícita, vejamos:

- Generalidade - quando se propôs a oferecer um serviço igual para todos os usuários, sejam eles os alunos ou a comunidade da região do semi-árido, que se traduz no oferecimento de todo e qualquer serviço que uma Unidade Acadêmica do campo do saber da Física de uma universidade deva prestar. Com isso poderá ser reconhecido o direito que todos (sejam da região do semi-árido baiano, ou de qualquer outra região do Brasil) têm de utilizar os serviços públicos da área de educação superior, sem se negar a um usuário o que foi concedido a outro,

- Permanência - quando se estabeleceu uma previsão de carga horária de longo prazo (10 anos), planejando a contratação de docentes nos momentos apropriados, levando sempre em conta a quantidade e a qualidade de atividades que o DFIS deveria realizar. Com isso a continuidade do serviço público que deveria ser prestado pelo DFIS poderia ser resguardada, sem correr risco de interrupção, 
- Eficiência - quando se estabeleceu um planejamento de capacitação dos docentes e de contratação de professores com a mais alta qualificação, bem como um planejamento de diretrizes para que as condições de trabalho (existência de um ambiente acadêmico, de personalidade acadêmica, distribuição de carga horária equilibrada para permitir a prática das atividades de pesquisa e extensão decorrentes da alta qualificação docente, ...) fossem satisfatórias. Com isso um serviço público atual seria oferecido à coletividade com o que houvesse de melhor, para a satisfação do bem comum,

- Modicidade - quando se estabeleceu um planejamento das atividades de ensino (através dos cursos de graduação e de pós-graduação), de pesquisa e de extensão para a comunidade de acordo com as tarifas praticadas pela universidade,

- Cortesia - quando se estabeleceu um planejamento das atividades de ensino (através dos cursos de graduação e de pós-graduação), de pesquisa e de extensão para a comunidade a serem praticadas por docentes qualificados. Com isso a expectativa subjacente foi a de que, devido à alta formação acadêmica dos agentes - os professores -, o DFIS ofereceria serviços com bom tratamento para o público, de forma cortês e educada, levando em conta que a prestação em tais condições não é favor do agente ou da administração pública - representada pelo DFIS -, mas dever de um e de outro e principalmente um direito do cidadão.

Um outro ponto a ser considerado é que o presente estudo revelou que, no aspecto das condições de trabalho dos professores de Física, as perspectivas advindas com a criação do departamento eram de:

- Consolidar o ambiente acadêmico propiciado a partir das implementações das ações delineadas no PCADFIS [23],

- Imprimir uma identidade acadêmica aos professores de Física, Propiciar condições para receber os professores de Física ao retornarem de suas respectivas pós-graduações,

- Criar uma massa crítica de docentes qualificados para propiciar uma atmosfera apropriada à pesquisa,

- Possibilitar o surgimento de grupos de pesquisa bem definidos nos vários sub-domínios da Física,

- Garantir uma carga horária de oito horas em sala de aula para um desenvolvimento equilibrado das atividades de ensino, pesquisa e extensão,

- Efetuar uma distribuição de carga horária condizente com a área de atuação do docente para permitir não só desdobramentos em relação a possíveis orientações dos estudantes, mas uma prática racional da atividade de ensino de acordo com a qualificação do docente (sem, no entanto, retirar do docente a possibilidade de ministrar aula de qualquer das disciplinas ofertadas pelo departamento),

- Montar a biblioteca setorial de Física,
- Instalar gabinetes apropriados para todos os professores de Física, com área de produção e de convivência,

- Implementar um planejamento administrativo que garanta aos docentes a efetivação de direitos do tipo licença-prêmio, licença sabática, afastamento para pós-graduação, afastamento para pós-doutorado, dentre outros.

Também, como um dado adicional para que a avaliação e comentários sobre a evolução do DFIS sejam fundamentados, consideraremos os argumentos e juízos exarados dos processos de criação [2] e implantação [3] do departamento de Física.

No processo de criação, exaustivamente discutido no CONSEPE, chama à atenção a leitura cuidadosa realizada pela relatora, professora Raquel de Matos Cardoso do Vale, preocupando-se em analisar cada um dos 10 capítulos do projeto do departamento [1] com o intuito de caracterizar, no seu parecer, o viés acadêmico que justificou a pertinência e a viabilidade da proposta de criação do Departamento de Física da UEFS. Com propriedade afirma: "Assim, qualquer proposta de ampliação do número de departamentos desta Universidade perpassa um viés acadêmico, uma vez que é em função da dinâmica das atividades de ensino, pesquisa e extensão de determinada área de conhecimento que se amplia seu quadro de professores, aumenta a sua qualificação docente, ou seja, o número de mestres e doutores, a produção científica, e por fim, a pluralidade do seu discurso acadêmico, [e] que nasce a demanda pelo desmembramento dos departamentos existentes" [2].

Dessa forma, do capítulo 1 (Introdução), ressaltou o compromisso da Área de Física, assumido em seu projeto [1], de

(i) Cumprir a meta estabelecida no Planejamento Estratégico [23] no que diz respeito ao Campo do Saber da Física na UEFS;

(ii) Garantir a manutenção do Ambiente Acadêmico que está sendo estabelecido devido às implementações das ações delineadas no PCAD-FIS [35, 36];

(iii) Dar uma Identidade Acadêmica aos seus Professores, posto que o citado Departamento congregará aqueles de formação acadêmica afim;

(iv) Garantir uma programação e uma execução efetivas das atividades de ensino, pesquisa e extensão em todos os Sub-Domínios da Física, dando ao DFIS-UEFS uma Personalidade Acadêmica clara e inconfundível;

(v) Possibilitar o cumprimento do papel de um Departamento, na medida em que serão adotadas e implementadas políticas efetivas de produção e transmissão do Conhecimento científico de Física, numa perspectiva extensionista de alcance social, outorgando à Universidade uma função transformadora do meio social; e,

(vi) Contribuir para que as aspirações de crescimento da UEFS, reveladas na Avaliação Institucional e no Planejamento Estratégico, tornem-se realidade, na medida em que o seu porte, assumido como pequeno no passado [24, 26, 27, 45-47], começará a ser modificado, possibilitando assim que a mesma possa assumir o efetivo perfil, tão almejado, de uma Universidade com pluridisciplinaridade de pesquisa, de extensão, e de formação de profissionais de nível superior. 
Do capítulo 2 (justificativa) relatou a necessidade de a UEFS rever a sua estrutura acadêmico-administrativa; do capítulo 3 (a universidade) citou a explanação sobre o processo de produção do conhecimento, envolvendo a cultura, o ser humano, o meio ambiente, e o tempo que fundamentou a consideração da Universidade ser o "locus que abriga os diversos saberes ou campos de saber do conhecimento humano" [2] e que, portanto, deve ser estruturada levando em conta as especificidades nos diversos campos do saber científico, literário e artístico; do capítulo 4 (a física) reuniu as considerações principais que mostram ser a Física um complexo e extenso campo do saber; do capítulo 5 (a física nas universidades públicas brasileiras) expôs a situação institucional que mostra que onde existe curso de Física, existe também departamento ou instituto próprio de Física; do capítulo 6 (O Departamento de Física da UEFS) mencionou a história do desenvolvimento da Física na UEFS, a definição do departamento, seus objetivos específicos, a proposta da estrutura acadêmico-administrativa com as quatro sub-unidades acadêmicas e as seis coordenações administrativas, listou as atividades de ensino, pesquisa e extensão existentes e as propostas, mencionou sobre a produção acadêmico-científica então vigente, sublinhou a programação de saídas e previsão da distribuição de carga horária docente para o decênio 1998-2007, bem como a qualificação docente no ano de 1998; do capítulo 7 (orçamento) pôs aspas no fato de que o projeto considerou a construção de espaço físico, de laboratório e aquisição de equipamentos e móveis; e do capítulo 8 (depoimentos) considerou os depoimentos de vários professores de diversas instituições, como o INPE, UNICAMP, UFBA, e USP, para frisar "o entusiasmo e a confiança com que vêem a Física na UEFS" [2].

Amparada nessas ênfases, com propriedade afirmou que "a proposta é, sem dúvida nenhuma, uma proposta de caráter acadêmico, denotando o profundo compromisso que os professores de Física têm com o seu curso e com esta Universidade" (grifo nosso) [2]. Pontuou que "em todos os capítulos verifica-se consistência, seriedade e convicção dos dados apresentados" [2], realçando que "fica evidenciado que a Área de Física possui, hoje [1998], um corpo de professores formados predominantemente por mestres e doutores, com programação detalhada para incrementação desta titulação e também do seu número de docentes" (grifo nosso) [2]. Arrematando, por fim, em relação às atividades de ensino, pesquisa e extensão que "estas atividades estão em franco desenvolvimento, com grande chance de diversificação e fortalecimento" (grifo nosso) [2]. "Nesse sentido, conclui a parecerista, resta-nos parabenizar a Área de Física e seus professores pela iniciativa de proporem a criação de um Departamento de Física, o que certamente abre a discussão sobre a atual estrutura organizacional desta Universidade" [2].

Após a leitura do parecer os membros do CONSEPE, em reunião realizada no dia 07 de outubro de 1998, discutiram o tema e, após ser ressaltado que "aliada ao entusiasmo do grupo que elaborou a proposta, existe a credibilidade do trabalho que é realizado pela Área de Física" [2], aprovaram a proposta de criação do Departamento de Física.

No processo de implantação [3], discutido no CONSU, a Comissão de Implantação do Departamento de Física estabeleceu, de acordo com o projeto do Departamento de Física: (a) o Plano de Trabalho resumido (2000-2004) das atividades fins, indicando que o detalhamento está contido no projeto [1]; (b) as Áreas de Conhecimento; e (c) as Disci- plinas oferecidas com os novos códigos. Acentua a comissão, como uma forma de cobrança da conclusão das obras, que os laboratórios didáticos do DFIS, após a construção do Anexo IV, serão lá instalados definitivamente; e que o DFIS pretende contratar professores para consolidar algumas áreas nas quais atua na pesquisa naquele momento (2000), sem descartar as outras, conforme o projeto aprovado.

A partir daí e amparando-se no projeto aprovado no CONSEPE, a relatora do processo de implantação, professora Maria do Socorro Costa São Mateus, tece os seus comentários, ressaltando a qualificação do corpo docente, a demanda de disciplinas que serão oferecidas à universidade, a estrutura administrativa composta das seis coordenações, a estrutura acadêmica composta das quatro sub-unidades acadêmicas, a previsão do Planejamento Estratégico da UEFS contemplando a existência do DFIS, a contextualização histórica que reconstitui a criação dos cursos na UEFS e os conseqüentes agrupamentos por departamentos, os trechos da Avaliação Institucional relativos à estrutura atual e a desejada, ressalta, também a vasta publicação técnico-científica do corpo docente do DFIS. Por fim, pontua os itens que embasaram e reforçaram a necessidade de criação do Departamento de Física, que resumidamente são [3]:

- A inadequação da estrutura atual da UEFS de acordo com a Avaliação Institucional e o Planejamento Estratégico, com departamentos sobrecarregados e excessivamente heterogêneos o que impede o surgimento da personalidade acadêmica dos próprios departamentos, pois existem aglomerados de Áreas de Conhecimento por departamento, cada uma com modus operandi, visão administrativa e acadêmica diferentes, impossibilitando uma efetiva programação e execução das atividades acadêmicas departamentais; e,

- A legalidade do projeto apresentado, na medida em que a legislação da UEFS e demais leis maiores não colocam impedimentos.

Considerando também que a exigência mínima de 12 membros havia sido atendida (na época existiam vinte (20) professores efetivos do Campo do Saber da Física) e que o princípio da não duplicação da organização dos departamentos e o da afinidade das disciplinas estavam contemplados, a parecerista exara um parecer favorável à implantação do Departamento de Física da UEFS, o qual foi aprovado pelos membros do CONSU em reunião realizada no dia $1^{\circ}$ de março de 2000.

Nesse sentido, a evolução do departamento a partir do ano de sua implantação, 2000, pode ser avaliada à luz das diretrizes e perspectivas delineadas no seu projeto de criação, levando em conta as considerações teóricofilosóficas subjacentes.

Para darmos prosseguimento à nossa avaliação, procuraremos destacar fatos importantes na evolução do DFIS, desde seu momento de efetiva implantação até o presente, analisando-os de acordo com as atividades desenvolvidas no mesmo.

Nas atividades de ensino planejadas e delineadas para o DFIS observamos que muitas das diretrizes supracitadas não foram implementadas, dificultando a execução adequada não só dessa como das demais atividades docentes. Por exemplo, é necessário um planejamento para a carga horária docente bem como uma adequada distribuição dela. Desejamos ressaltar com isto que para existir uma atuação docente plena nas atividades do departamento, i.e., além do 
ensino, como também na pesquisa, na extensão e na administração, é imprescindível uma carga horária não superior às $8 \mathrm{~h}$ por semana, uma vez que a atividade de ensino se estende muito além da sala de aula, a saber, com as atividades complementares (planejamento, preparação de aulas, preparação e correção de listas, atendimento individual extraclasse de alunos, tempo programado para a dedicação do aluno(a) à disciplina, e outros). Ademais, cumpre notar a necessidade de uma programação na distribuição da carga horária, desde que a preparação de curso, seja da graduação seja da pós-graduação, requer do docente um tempo de dedicação apropriado. Observemos que esta é uma das tarefas que deveria desempenhar a Coordenação de Ensino, a distribuição de carga horária, de forma a geri-la com eficiência, levando em conta a alocação de professores nas disciplinas de acordo com seu perfil de atuação, realçando, com efeito, a liberdade de escolha pelo próprio docente de ministrar aulas de qualquer das disciplinas do departamento.

Outra questão de vital importância e que se tem constituído num grande problema para todos os cursos ligados e atendidos pelo DFIS é o dos laboratórios didáticos de Física. A precariedade destes laboratórios tem acarretado problemas de diferentes ordens, inclusive, no aspecto do reconhecimento do curso de Física (conforme alertado pela própria comissão de verificação do CEE - Conselho Estadual de Educação). A falta de uma adequada estrutura física dos 12 laboratórios tanto quanto de equipamentos e de abordagem de ensino de laboratório (esta última já considerada em projeto de pesquisa de professores do DFIS, mas não implementada [31-34]) tem comprometido de forma irreparável os cursos de graduação. Ao mesmo tempo não tem existido de forma efetiva a ação da Coordenação dos Laboratórios Didáticos do DFIS como previsto em seu projeto. As ações dessa coordenação dirigem-se precisamente no sentido de evitar os problemas citados, ou outros que por ventura venham a ocorrer com os laboratórios didáticos.

Também a implantação dos cursos de pós-graduação (especialização, mestrado e doutorado), deixou de ser cumprida como prevista no projeto do DFIS. A falta de uma pós-graduação está naturalmente associada à falta de uma massa crítica de pesquisadores no DFIS (frisese, contudo, contemplada na programação explicitada na Tabela II) capaz de estabelecer as condições mínimas para a criação das áreas de concentração do departamento. Conseqüentemente, sem um programa de pós-graduação, a própria atividade de pesquisa do departamento torna-se significativamente reduzida.

Apesar do aumento (subestimado) do número de docentes no departamento, a natural necessidade de espaço físico para gabinetes de professores provocou uma ocupação indevida dos espaços do anexo de laboratórios de Física, desviando assim a utilização originalmente prevista para os mesmos [38] que era a alocação dos 12 laboratórios didáticos do departamento.

Nesse sentido, observamos que a inexistência da Coordenação de Ensino dificultou decisivamente a implementação das diretrizes e metas atinentes à Sub-Unidade de Ensino.

Também na atividade de pesquisa destacamos algumas observações importantes. Em primeiro lugar podemos retomar a questão já abordada da massa crítica. A existência de uma massa crítica de doutores no campo do saber da Física é crucial, primordialmente para possibilitar o exercício da pesquisa em sua plenitude, como também para o atendimento dos requisitos da generalidade, permanência e eficiência do serviço público, de uma forma geral.

Mais especificamente, a falta de uma massa crítica impossibilitou o estabelecimento dos grupos de pesquisa do DFIS, a ampliação desses grupos e a natural consolidação das linhas de pesquisa em que o departamento atuaria. Cabe lembrar que estas linhas de pesquisa constituirão as linhas de pesquisa para uma futura pós-graduação no campo das ciências físicas na UEFS. Ao mesmo tempo, a consolidação das linhas de pesquisa deveria vir como resultado de uma política do departamento voltada para a consolidação dos próprios grupos de pesquisa. Uma vez que deixou de ser implementada tal política de pesquisa de acordo com as diretrizes delineadas, também deixou de existir uma ação departamental que estimulasse a prática de ações supradisciplinares entre o DFIS e outros grupos de pesquisa da universidade.

Os objetos das pesquisas referidas no parágrafo anterior, conforme delineado na natureza da atividade de pesquisa devem incluir os temas globais e gerais do campo do saber da Física bem como aqueles voltados para o desenvolvimento autônomo e sustentável da região do semi-árido, ou seja, a contribuição que a Física pode colocar (e tem colocado, mas não ainda na sua plenitude) para os problemas de caráter regional.

Embora seja reconhecida a necessidade de espaços para os gabinetes de professores, os espaços do anexo de laboratórios de Física eram, de acordo com o projeto do DFIS, voltados para os laboratórios didáticos de Física e havia a previsão de alguns espaços para os laboratórios de pesquisa. Com isso, houve uma ocupação indevida do anexo com os gabinetes comprometendo a implantação dos referidos laboratórios, comprometendo também a dotação orçamentária que levou à construção do anexo de laboratórios [39]. Sem os espaços físicos e um projeto específico tratando da implantação dos laboratórios de pesquisa se inviabilizou também a dotação orçamentária voltada para a aquisição dos equipamentos para os mesmos [39].

Dessa forma, assim como a falta de uma Coordenação de Ensino trouxe problemas para o departamento, a falta de uma Coordenação de Pesquisa trouxe prejuízos de outra ordem. O papel da Coordenação de Pesquisa, delineado mais acima, é o de coordenar e auxiliar o desenvolvimento das atividades de pesquisa do DFIS. Sendo assim, a organização, o planejamento e o acompanhamento das atividades de pesquisa do DFIS passa fundamentalmente pela sua Coordenação de Pesquisa, a qual deveria estimular a implementação dos laboratórios de pesquisa, de uma biblioteca setorial, dos grupos e das respectivas linhas de pesquisa entre outras atribuições, bem como deveria preocupar-se, juntamente com a Coordenação de Ensino, com a criação dos cursos de pós-graduação (especialização, mestrado e doutorado).

Por fim, mas não menos importante, cabe ressaltar o não cumprimento pleno do planejamento de capacitação dos professores do DFIS na medida em que, no retorno de suas pós-graduações, eles não encontram um ambiente propício para implementarem as suas potencialidades adquiridas, não só no que tange à pesquisa, mas também ao ensino.

No aspecto das atividades de extensão outros pontos podem ser mencionados. Chama a atenção o fato de que a Coordenação de Extensão também não foi implementada. Com isso, inexistiu a aplicação do planejamento das atividades de extensão, bem como o cumprimento de suas finalidades. Esses fatos indubitavelmente trazem como conseqüência uma descaracterização completa da atividade de 
extensão, significando que foi relegada; um fato em franca contradição com a concepção de extensão em Física estabelecida no projeto do DFIS. Um alcance negativo disto é o de perpetuar na sociedade, em particular na região do semi-árido, a visão distorcida da Física e dos físicos: a Física como uma disciplina 'difícil', só cultivada-estudadapesquisada por 'iluminados'; e os físicos como pessoas 'estranhas' e muitas vezes arrogantes, distantes da realidade das coisas.

Por outro lado, uma vez que a massa crítica, já aludida, não foi estabelecida, também não se estabeleceram as condições objetivas para uma ação extensionista ampla atendendo não só as diretrizes gerais sobre a prática de tal atividade, como também as definições dos próprios atos extensionistas. Além disso, não foram criados grupos de extensão o que acarretou uma falta de intra e inter relações de atividades daí decorrentes.

No que tange aos cursos de pós-graduação, a sua não implantação inviabilizou o cumprimento de um importante papel da extensão como articuladora das atividades de ensino e de pesquisa com a sociedade. Nessa linha, vale ressaltar uma importante diretriz delineada que não foi posta em prática: a estruturação do laboratório de extensão LEF-FIS, o qual visava atender inicialmente, mas não exclusivamente, docentes do primeiro grau da rede pública.

No aspecto das atividades de extensão que estavam em desenvolvimento e aquelas em estágio de proposição, observou-se que: houve uma parada total das atividades "Interações Extensionistas em Física", "Difusão de Física no $1^{\circ}$ e $2^{\circ}$ graus", e "Notas de Física"; há uma falta de periodicidade das atividades "Colóquios de Física", "Seminários de Física", "Caderno de Física", e "Escola de Verão do Departamento de Física"; inexistem ações que se proponham à realização do projeto "Curso de Aperfeiçoamento para Professores de Física do $2^{\circ}$ grau".

Abordando a inovadora atividade de apoio acadêmico, avaliemos os pontos que a consubstanciam. Vale ressaltar que, devido ao caráter inovador, esse é um ponto merecedor de especial atenção.

A meta prioritária das ações atinentes à atividade de apoio acadêmico é o desenvolvimento equilibrado, harmônico e homogêneo da Unidade Acadêmica DFIS.

Do ponto de vista filosófico-conceitual, a existência da atividade de apoio acadêmico surgiu como uma proposta ousada para uma problemática conhecida nas universidades, relacionada com a estrutura departamental, e que pode ser sintetizada em termos de uma desarmonia, individualização, burocratização e hierarquização das ações de um departamento, de acordo com os trabalhos de Graciani [48], levando a uma falta de integração e apatia entre os professores, bem como a um desestímulo para a prática das atividades docentes voltadas para o coletivo. Um processo que levou, como é sabido, a um profundo questionamento da própria estrutura universitária alicerçada em departamentos. Como uma alternativa dentro da estrutura departamental [1], foi proposta a atividade de apoio acadêmico que objetiva diluir a desarmonia, individualização e apatia dos professores através de atividades de cunho coletivo, harmonizador e que estimulem a auto-estima, segurança e o diálogo, com um viés educativo e socializador. Claro está que tais atividades atacam o efeito proporcionado pela problemática aludida; no entanto, em conjunção com a ousada concepção de estrutura acadêmico-administrativa do DFIS, como estabelecida em [1], tem-se uma alternativa para enfrentar a própria problemática.
O papel da Coordenação de Apoio Acadêmico, portanto, é o de estimular e propiciar o bom desenvolvimento de todas as atividades do departamento bem como de constituirse num referencial de primeira instância para dirimir as questões que propiciem distensões, estimulando as partes para um diálogo fraterno na busca de soluções harmoniosas. Considera-se, então, que a Coordenação de Apoio Acadêmico juntamente com a Coordenação Geral do departamento devem trabalhar em consonância para promover um ambiente harmônico, de integração nas ações e de estímulo para o desenvolvimento das atividades docentes no departamento.

Sendo assim, a inexistência da Coordenação de Apoio sinaliza os efeitos da problemática aludida acima, ou seja, atitudes isoladas e individualizadas dos docentes do departamento. A implementação da Coordenação de Apoio Acadêmico, de acordo com o projeto do DFIS, será extremamente positiva tanto para a direção do departamento quanto para o corpo docente, desde que tal coordenação trabalhará em conjunto pela concretização da biblioteca setorial de Física, dos laboratórios de apoio, das oficinas de apoio, bem como das atividades que estimularão a criação de grupos de pesquisa e extensão e das atividades que estimularão a criação de interdependências e ajudas mútuas.

A falta de compreensão do verdadeiro significado e natureza das atividades de apoio acadêmico dificultou a instalação e atuação da respectiva coordenação, bem como propiciou a inexistência da própria atividade no DFIS. Com isso perdeu-se o papel que destacaria uma clara política de integração no seio do departamento buscando a realização dos anseios docentes.

Consideradas as atividades acadêmicas, passemos ao estudo das atividades eminentemente administrativas.

Como já ressaltado nos parágrafos anteriores, as Coordenações de Ensino, de Pesquisa, de Extensão e de Apoio Acadêmico não foram efetivamente implementadas. De início convêm ressaltar que, conceitualmente, a existência de coordenador não implica na existência de coordenação. As cinco coordenações, juntamente com o conselho departamental, constituem-se, por definição, nos organismos colegiados que compõem a Estrutura Administrativa do DFIS. Diferentemente do conselho departamental, que é composto dos professores do campo do saber da Física, integrantes da carreira do magistério, as coordenações são compostas por representantes de atividades (ou atributos) previamente definidas.

Dessa forma, a constituição das Coordenações de Ensino, de Pesquisa, de Extensão e de Apoio Acadêmico independerá da vontade do corpo dirigente do departamento (a Coordenação Geral do departamento). Nesse sentido, tais coordenações proporcionarão no departamento um tom de pluralidade e de respeito à minoria posto que qualquer professor, investido da atividade ou atributo definidor da coordenação, assumirá a representação respectiva. Além disso, a existência de tais coordenações, juntamente com a Coordenação Geral, reafirma os princípios fundamentais que regem uma boa administração na medida em que elas compõem um agente harmonizador das atividades administrativas, possibilitam efetivamente uma descentralização das ações administrativas, garante a delegação de competências, e participa do exercício democrático e sereno da fiscalização-acompanhamento do cumprimento da lei e das normas, bem como das atividades docentes no sentido da educação e orientação dos professores.

Como não foram implementadas as coordenações aludi- 
das, concluímos que, em geral, no Departamento de Física não se instaurou o acento da pluralidade e do respeito à minoria. Além disso, os princípios da coordenação, descentralização, delegação de competências e acompanhamento não foram implementados.

Pode-se afirmar, conseqüentemente, que não existe uma divisão das responsabilidades através das coordenações aludidas, acarretando em uma centralização do poder, o que, por outro lado, indica uma sobrecarga nas atividades administrativas desempenhadas pelo corpo diretivo do departamento.

Em suma, afirmamos que não existe uma compreensão do significado e natureza das atividades administrativas como assinaladas no projeto de criação do Departamento de Física.

Queremos chamar a atenção de que dentre as diretrizes traçadas para tal atividade, algumas ainda não foram cumpridas das quais se podem citar: não efetivação de funcionários técnico-administrativos com formação em administração, contabilidade e direito para darem o suporte apropriado para o bom andamento administrativo-contábillegal do departamento; espaço físico inadequado da sede do departamento na medida em que está isolada da estrutura física que comporta as atividades acadêmicas; e instalação dos gabinetes em local inapropriado, como já ressaltado, e em número abaixo do necessário.

Um ponto importante e inovador que vale a pena ser tocado, relaciona-se com a proposta da estrutura acadêmicoadministrativa da Unidade Acadêmica de Física. Ela foi pensada para possibilitar a divisão de responsabilidades, a efetiva participação do conjunto de professores e o relacionamento orgânico do DFIS com os outros órgãos colegiados da Universidade, bem como da própria comunidade universitária.

No aspecto do relacionamento orgânico, a Coordenação de Ensino tem um papel fundamental na medida em que será o local natural de discussão da qualidade do serviço que o DFIS presta a toda a Universidade quando oferece as disciplinas aos cursos existentes e por existir, avaliando as características, objetivos e diferenças existentes entre cada um deles, respeitando as suas diferentes naturezas, contribuindo, assim, para a realização das ações supradisciplinares no que tange ao ensino. Com isso, os professores representantes das matérias nos colegiados dos diversos cursos atendidos pelo departamento poderão ter uma ação efetiva e a ligação "colegiados - departamento" será de fato respeitadora do papel de cada um e orgânica.

Por sua vez, ainda no aspecto orgânico aludido, a Coordenação de Pesquisa cumprirá seu papel de permanente estímulo ao desenvolvimento das variadas pesquisas existentes e por existir no Campo do Saber da Física, estimulando a interação docente com os pesquisadores de outras Unidades Acadêmicas da universidade, abrindo o caminho para as ações supradisciplinares no que tange à pesquisa. Dessa forma, além do DFIS contribuir para o desenvolvimento técnico-científico-tecnológico-social da região de forma autônoma com as suas pesquisas específicas, irá participar, com as pesquisas supradisciplinares, do processo de construção do conhecimento universitário ao compreender a pesquisa como uma atitude de vida, estratégia básica de autoconstrução.

A Coordenação de Extensão, também, terá um papel semelhante, pois propiciará a participação do DFIS em atividades de extensão com um viés humanístico objetivando não só conscientizar a comunidade sobre a reali- dade, sobre o pensamento, sobre a prática da vida, no que tange ao conhecimento físico, mas contribuindo para que a Universidade transforme-se em um local de vida agradável, através de projetos que se caracterizem pela busca da estética, enquanto desejo.

Por fim, embora as figuras dos Coordenadores de Ensino, de Pesquisa, e de Extensão, tenham existido, como tradicionalmente ocorre em outros departamentos da UEFS, o elemento diferenciador e inovador colocado com a Coordenação Geral, e detalhado na referência [1], não se concretizou, e conseqüentemente o espírito das quatro coordenações (mais amplas que seus coordenadores) foi perdido.

Dessa forma, o conjunto dessas análises e comentários sobre a evolução do DFIS mostra que os princípios de planejamento, coordenação, descentralização, delegação de competências, e acompanhamento, que fundamentam a boa administração, não têm sido satisfeitos no DFIS, bem como não têm sido atendidos os requisitos do serviço publico de generalidade, permanência, e eficiência, mostrando que o DFIS, essencialmente esta seguindo os preceitos tradicionais da visão departamental o que está em franca contradição com a proposta ousada elaborada no seu projeto de criação.

\section{CONCLUSÕES}

O presente trabalho faz uma análise crítica da evolução do Departamento de Física da Universidade Estadual de Feira de Santana.

Considerou, do projeto de criação, os pressupostos teórico-filosóficos sobre o processo de produção do conhecimento humano envolvendo a cultura, o ser humano, o meio ambiente e o tempo, que fundamentaram a concepção de universidade e de unidade acadêmica assumidos e que serviram de base para estabelecer, naquele momento, a estrutura institucional de departamento para o Campo do Saber da Física, e considerou, dos pareceres de criação e implantação, os pontos relevantes que foram arrolados nos respectivos processos para justificar a aprovação do projeto nas instâncias superiores da universidade.

A partir daí, à luz das diretrizes e perspectivas delineadas no projeto, realizamos uma análise da evolução do departamento desde a sua implantação, no ano de 2000, até a atualidade, considerando as atividades, nele, desenvolvidas.

Como ficou evidente no estudo feito, expectativa inclusive das instâncias superiores [2, 3], o corpo docente formador do departamento no final desses cinco anos deveria conter 51 professores, conforme a Tabela II, número importante para possibilitar, como planejado, a existência da denominada massa crítica docente. Com isso, o conjunto de atividades propostas no projeto estaria em condições de ser implementado ao longo desses cinco anos de vida, além do que possibilitaria a atuação do departamento em um número maior de áreas do Campo do Saber da Física, fator importante para o desejado desenvolvimento da região.

No que tange à atividade de ensino, o curso de graduação poderia ser reestruturado de tal forma a permitir várias ênfases e habilitações, tão fundamentais para a inserção de profissionais nos campos de trabalho da região, além do que o departamento poderia ter contribuído na importante discussão do ensino de laboratório ao implementar a filosofia de ensino de laboratório baseada na abordagem epistemológica. Ainda nessa linha, e considerando o 
papel fundamental da universidade garantir um processo de desenvolvimento sócio-econômico-científico-tecnológico autônomo para a sociedade, a massa crítica aludida teria criado as condições objetivas para a criação dos cursos de especialização (que atenderia a heterogeneidade das áreas de demanda, no mercado de trabalho) e de mestrado e doutorado (que possibilitaria ao diplomado exercer funções científicas), na medida em que se teriam grupos de pesquisa mais bem definidos e atuantes, com maiores chances de consolidação.

Além disso, as atividades de extensão teriam se firmado como integradoras do departamento com a sociedade na medida em que o DFIS teria atuado no sentido de reverter seus benefícios em favor da população, bem como teria articulado o ensino e a pesquisa com a sociedade em um viés transformador do meio social.

Nesse sentido, com uma atuação efetiva no que tange ao conjunto das atividades docentes, o departamento teria cumprido, até então, a parte que lhe diz respeito no tocante ao estabelecimento de condições de trabalho ade- quadas para os professores, como eram as perspectivas advindas com a sua criação.

Urge, portanto, a retomada dos rumos que foram fundamentais para a própria criação do Departamento de Física. Não podemos perder de vista que a organização institucional de uma entidade (no nosso caso, a universidade em geral, e o departamento, em particular) que objetiva a formação de profissionais de nível superior, bem como a pluridisciplinaridade de pesquisa e de extensão, tem como função precípua dar condições para que tais objetivos ocorram. Isso significa, conseqüentemente, que o Departamento de Física deve assumir o seu verdadeiro papel e dar condições para que os cursos de Física (de graduação e de pós-graduação), bem como as atividades de pesquisa e extensão, ocorram na sua plenitude posto que tais atividades têm um papel fundamental no desenvolvimento das pessoas e da sociedade, sendo um dos elementos essenciais para favorecer as transformações sociais necessárias que a região do semi-árido carece, pontos, aliás, historicamente sempre defendidos pelos profissionais da Física da UEFS. 


\begin{tabular}{|c|c|c|c|c|c|c|c|c|c|c|c|c|c|c|c|c|c|c|c|c|}
\hline \multirow{2}{*}{$\begin{array}{c}\text { Ano/ } \\
\text { Semestre } \\
\text { Professor }\end{array}$} & \multicolumn{2}{|c|}{1998} & \multicolumn{2}{|c|}{1999} & \multicolumn{2}{|c|}{2000} & \multicolumn{2}{|c|}{2001} & \multicolumn{2}{|c|}{2002} & \multicolumn{2}{|c|}{2003} & \multicolumn{2}{|c|}{2004} & \multicolumn{2}{|c|}{2005} & \multicolumn{2}{|c|}{2006} & \multicolumn{2}{|c|}{2007} \\
\hline & $s_{1}$ & $S_{2}$ & $s_{1}$ & $S_{2}$ & $s_{1}$ & $S_{2}$ & $s_{1}$ & $S_{2}$ & $s_{1}$ & $s_{2}$ & $s_{1}$ & $S_{2}$ & $s_{1}$ & $S_{2}$ & $s_{1}$ & $S_{2}$ & $s_{1}$ & $S_{2}$ & $s_{1}$ & $S_{2}$ \\
\hline $\begin{array}{c}\text { Alberto São } \\
\text { Paulo }\end{array}$ & $M$ & $\mathrm{M}$ & M & $M$ & 08 & 08 & $D$ & D & D & $D$ & $D$ & $D$ & D & D & 08 & 08 & 08 & 08 & 08 & 08 \\
\hline $\begin{array}{c}\text { Álvaro S. } \\
\text { Alves }\end{array}$ & 12 & 08 & 08 & 08 & 08 & $D$ & $D$ & D & D & $D$ & $D$ & $D$ & D & 08 & 08 & 08 & 08 & 08 & 08 & 08 \\
\hline $\begin{array}{l}\text { Antônio } \\
\text { Delson }\end{array}$ & $D$ & 08 & 08 & 08 & 08 & 08 & 08 & 08 & 08 & 08 & 08 & 08 & 08 & 08 & 08 & 08 & 08 & 08 & 08 & 08 \\
\hline $\begin{array}{c}\text { Antônio } \\
\text { Jorge }\end{array}$ & 08 & 08 & 08 & 08 & D & $D$ & $D$ & D & D & $D$ & $D$ & $\mathrm{D}$ & 08 & 08 & 08 & 08 & 08 & 08 & 08 & 08 \\
\hline $\begin{array}{c}\text { Antônio } \\
\text { Neto }\end{array}$ & $D$ & $\mathrm{D}$ & D & D & $D$ & $D$ & 08 & 08 & 08 & 08 & 08 & 08 & 08 & 08 & 08 & 08 & 08 & 08 & 08 & 08 \\
\hline $\begin{array}{c}\text { Dagoberto } \\
\text { Freitas } \\
\end{array}$ & D & $\mathrm{D}$ & D & D & 08 & 08 & 08 & 08 & 08 & 08 & 08 & 08 & 08 & 08 & 08 & 08 & 08 & 08 & 08 & 08 \\
\hline $\begin{array}{c}\text { Durval } \\
\text { Eusíquio }\end{array}$ & 08 & $\mathrm{M}$ & $\mathrm{M}$ & M & 08 & 08 & 08 & 08 & 08 & 08 & 08 & 08 & 08 & 08 & 08 & 08 & 08 & 08 & 08 & 08 \\
\hline Elder Sales & 09 & 08 & M & $\mathrm{M}$ & $\mathrm{M}$ & $\mathrm{M}$ & $M$ & M & 08 & 08 & 08 & 08 & 08 & 08 & 08 & 08 & 08 & 08 & 08 & 08 \\
\hline Franz Peter & 08 & 08 & D & D & $D$ & $D$ & $D$ & D & $D$ & $D$ & 08 & 08 & 08 & 08 & 08 & 08 & 08 & 08 & 08 & 08 \\
\hline $\begin{array}{l}\text { Jailton } \\
\text { Souza }\end{array}$ & 08 & 08 & D & D & $D$ & $D$ & $D$ & D & $D$ & $D$ & 08 & 08 & 08 & 08 & 08 & 08 & 08 & 08 & 08 & 08 \\
\hline Jairo Rocha & 08 & 08 & 08 & 08 & 08 & 08 & 08 & 08 & 08 & 08 & 08 & 08 & 08 & 08 & 08 & 08 & 08 & 08 & 08 & 08 \\
\hline Jean Lessa & 08 & 08 & 08 & 08 & D & $D$ & $D$ & D & $D$ & D & D & $\mathrm{D}$ & 08 & 08 & 08 & 08 & 08 & 08 & 08 & 08 \\
\hline $\begin{array}{c}\text { José Carlos } \\
\text { de Jesus }\end{array}$ & 08 & 08 & 08 & 08 & 08 & 08 & 08 & 08 & 08 & 08 & 08 & 08 & 08 & 08 & 08 & 08 & 08 & 08 & 08 & 08 \\
\hline $\begin{array}{c}\text { Marcelo } \\
\text { Moret }\end{array}$ & $D$ & $\mathrm{D}$ & D & D & $D$ & 08 & 08 & 08 & 08 & 08 & 08 & 08 & 08 & 08 & 08 & 08 & 08 & 08 & 08 & 08 \\
\hline $\begin{array}{l}\text { Milton } \\
\text { Ribeiro }\end{array}$ & 08 & 08 & D & D & D & $D$ & $D$ & D & $D$ & $D$ & 08 & 08 & 08 & 08 & 08 & 08 & 08 & 08 & 08 & 08 \\
\hline $\begin{array}{c}\text { Nildon } \\
\text { Pitombo }\end{array}$ & 08 & 08 & 08 & 08 & 08 & 08 & 08 & 08 & 08 & 08 & 08 & 08 & 08 & 08 & 08 & 08 & 08 & 08 & 08 & 08 \\
\hline $\begin{array}{l}\text { Paulo } \\
\text { Poppe }\end{array}$ & 04 & 10 & 08 & 08 & 08 & 08 & 08 & 08 & 08 & 08 & 08 & 08 & 08 & 08 & 08 & 08 & 08 & 08 & 08 & 08 \\
\hline $\begin{array}{c}\text { Rainer } \\
\text { Madejsky }\end{array}$ & 04 & 04 & - & - & 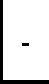 & - & - & - & - & - & 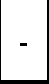 & - & - & - & - & - & - & - & - & - \\
\hline $\begin{array}{c}\text { Rosa } \\
\text { Bunchaft }\end{array}$ & 09 & 08 & D & D & $D$ & $D$ & $D$ & $\mathrm{D}$ & $D$ & $D$ & 08 & 08 & 08 & 08 & 08 & 08 & 08 & 08 & 08 & 08 \\
\hline $\begin{array}{c}\text { Sérgio } \\
\text { Azevedo }\end{array}$ & 10 & 08 & 08 & 08 & 08 & 08 & 08 & 08 & 08 & 08 & 08 & 08 & 08 & 08 & 08 & 08 & 08 & 08 & 08 & 08 \\
\hline $\begin{array}{c}\text { Thierry } \\
\text { Lemaire }\end{array}$ & 08 & 08 & 08 & 08 & 08 & 08 & 08 & 08 & 08 & 08 & 08 & 08 & 08 & 08 & 08 & 08 & 08 & 08 & 08 & 08 \\
\hline $\begin{array}{c}\text { Vera } \\
\text { Aparecida }\end{array}$ & 08 & 08 & 08 & 08 & 08 & 08 & 08 & 08 & 08 & 08 & 08 & 08 & 08 & 08 & 08 & 08 & 08 & 08 & 08 & 08 \\
\hline ProfEC $_{01}$ & - & 10 & 08 & 08 & 08 & 08 & 08 & 08 & 08 & 08 & 08 & 08 & 08 & 08 & 08 & 08 & 08 & 08 & 08 & 08 \\
\hline
\end{tabular}




\begin{tabular}{|c|c|c|c|c|c|c|c|c|c|c|c|c|c|c|c|c|c|c|c|c|}
\hline \multirow{2}{*}{$\begin{array}{c}\text { Ano/ } \\
\text { Semestre } \\
\text { Professor }\end{array}$} & \multicolumn{2}{|c|}{1998} & \multicolumn{2}{|c|}{1999} & \multicolumn{2}{|c|}{2000} & \multicolumn{2}{|c|}{2001} & \multicolumn{2}{|c|}{2002} & \multicolumn{2}{|c|}{2003} & \multicolumn{2}{|c|}{2004} & \multicolumn{2}{|c|}{2005} & \multicolumn{2}{|c|}{2006} & \multicolumn{2}{|c|}{2007} \\
\hline & $S_{1}$ & $S_{2}$ & $s_{1}$ & $S_{2}$ & $s_{1}$ & $S_{2}$ & $s_{1}$ & $S_{2}$ & $s_{1}$ & $S_{2}$ & $s_{1}$ & $S_{2}$ & $s_{1}$ & $S_{2}$ & $s_{1}$ & $S_{2}$ & $S_{1}$ & $S_{2}$ & $s_{1}$ & $S_{2}$ \\
\hline $\mathrm{C}_{02}$ & - & & 2 & 0 & 8 & 8 & 8 & 08 & 8 & 08 & 08 & 08 & 8 & 08 & 08 & 08 & 88 & 08 & 08 & 08 \\
\hline ProfEC $_{03}$ & - & & 12 & 08 & 08 & 08 & 08 & 08 & 08 & 08 & 08 & 08 & 08 & 08 & 08 & 08 & 08 & 08 & 08 & 08 \\
\hline Prof & - & - & 12 & 08 & 08 & 08 & 08 & 08 & 08 & 08 & 08 & 08 & 08 & 08 & 08 & 08 & 08 & 08 & 08 & 08 \\
\hline ProfEC $_{05}$ & - & - & 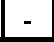 & 12 & 08 & 08 & 08 & 08 & 08 & 08 & 08 & 08 & 08 & 08 & 08 & 08 & 08 & 08 & 08 & 08 \\
\hline ProfE & - & - & - & 12 & 08 & 08 & 08 & 08 & 08 & 08 & 08 & 08 & 08 & 08 & 08 & 08 & 08 & 08 & 08 & 08 \\
\hline Prof & - & 04 & 08 & 08 & 08 & 08 & 08 & 08 & 08 & 08 & 08 & 08 & 08 & 08 & 08 & 08 & 08 & 08 & 08 & 08 \\
\hline ProfVC $_{02}$ & - & 08 & 08 & 10 & 08 & 08 & 08 & 08 & 08 & 08 & 08 & 08 & 08 & 08 & 08 & 08 & 08 & 08 & 08 & 08 \\
\hline ProfVC $_{03}$ & - & & 08 & 08 & 08 & 08 & 08 & 08 & 08 & 08 & 08 & 08 & 08 & 08 & 08 & 08 & 08 & 08 & 08 & 08 \\
\hline ProfvC $_{04}$ & - & - & 10 & 10 & 08 & 08 & 08 & 08 & 08 & 08 & 08 & 08 & 08 & 08 & 08 & 08 & 08 & 08 & 08 & 08 \\
\hline ProfVC $_{05}$ & - & - & 10 & 08 & 08 & 08 & 08 & 08 & 08 & 08 & 08 & 08 & 08 & 08 & 08 & 08 & 08 & 08 & 08 & 08 \\
\hline ProfvC $_{06}$ & - & - & 10 & 08 & 08 & 08 & 08 & 08 & 08 & 08 & 08 & 08 & 08 & 08 & 08 & 08 & 08 & 08 & 08 & 08 \\
\hline ProfvC $_{07}$ & - & - & 08 & 08 & 08 & 08 & 08 & 08 & 08 & 08 & 08 & 08 & 08 & 08 & 08 & 08 & 08 & 08 & 08 & 08 \\
\hline ProfvC $_{08}$ & - & - & - & 08 & 08 & 08 & 08 & 08 & 08 & 08 & 08 & 08 & 08 & 08 & 08 & 08 & 08 & 08 & 08 & 08 \\
\hline ProfVC & - & - & - & 08 & 08 & 08 & 08 & 08 & 08 & 08 & 08 & 08 & 08 & 08 & 08 & 08 & 08 & 08 & 08 & 08 \\
\hline ProfvC $_{10}$ & - & - & - & 10 & 08 & 08 & 08 & 08 & 08 & 08 & 08 & 08 & 08 & 08 & 08 & 08 & 08 & 08 & 08 & 08 \\
\hline Pro & - & - & - & 08 & 08 & 08 & 08 & 08 & 08 & 08 & 8 & 08 & 8 & 08 & 08 & 08 & 08 & $\underline{0}$ & 8 & 08 \\
\hline Pro & - & - & - & 08 & 08 & 08 & 08 & 08 & 8 & 08 & 08 & 08 & 08 & 8 & 08 & 08 & 08 & 08 & 08 & 0 \\
\hline Prof & - & - & - & 10 & 08 & 08 & 08 & 08 & 08 & 08 & 08 & 08 & 08 & 08 & 08 & 08 & 08 & 08 & 08 & 08 \\
\hline Pro & - & - & - & - & 08 & 08 & 08 & 08 & 08 & 08 & 08 & 08 & 08 & 08 & 08 & 08 & 08 & 08 & 08 & 08 \\
\hline ProfVC $_{15}$ & - & - & - & - & 08 & 08 & 08 & 08 & 08 & 08 & 08 & 08 & 08 & 08 & 08 & 08 & 08 & 08 & 08 & 08 \\
\hline ProfvC $_{16}$ & - & - & - & - & 08 & 08 & 08 & 08 & 08 & 08 & 08 & 08 & 08 & 08 & 08 & 08 & 08 & 08 & 08 & 08 \\
\hline ProfVC $_{17}$ & - & - & - & - & 10 & 08 & 08 & 08 & 08 & 08 & 08 & 08 & 08 & 08 & 08 & 08 & 08 & 08 & 08 & 08 \\
\hline ProfvC $_{18}$ & - & - & - & - & 10 & 08 & 08 & 08 & 08 & 08 & 08 & 08 & 08 & 08 & 08 & 08 & 08 & 08 & 08 & 08 \\
\hline ProfVC $_{19}$ & - & - & - & - & - & 08 & 08 & 08 & 08 & 08 & 08 & 08 & 08 & 08 & 08 & 08 & 08 & 08 & 08 & 08 \\
\hline ProfVC $_{20}$ & - & - & - & - & - & 08 & 08 & 08 & 08 & 08 & 08 & 08 & 08 & 08 & 08 & 08 & 08 & 08 & 08 & 08 \\
\hline ProfVC $_{21}$ & - & - & - & - & - & 08 & 08 & 08 & 08 & 08 & 08 & 08 & 08 & 08 & 08 & 08 & 08 & 08 & 08 & 08 \\
\hline $\mathrm{P}$ & - & - & - & - & & 08 & 08 & 08 & 8 & 08 & 08 & 08 & 08 & 8 & 08 & 08 & 08 & 08 & 08 & 08 \\
\hline Pro & - & - & - & - & - & - & 8 & 08 & 08 & 08 & 08 & 08 & 08 & 8 & 08 & 08 & 08 & 08 & 08 & 08 \\
\hline Pro & - & - & - & - & 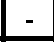 & - & 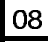 & 08 & 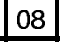 & 08 & 08 & c & 08 & 3 & 08 & 08 & 08 & 08 & 08 & 08 \\
\hline $\begin{array}{c}\text { Carga } \\
\text { Horária } \\
\text { Docente } \\
\text { total, }\end{array}$ & & & 94 & & & 320 & & & & & & & & 40 & 40 & 40 & 408 & 40 & 408 & 408 \\
\hline $\begin{array}{l}\text { Horária em } \\
\text { Sala de } \\
\text { Aula, por } \\
\text { semana }\end{array}$ & & & & & & & & & & & & & & & & & & & & pou \\
\hline
\end{tabular}

Tab. II - Previsão de Carga Horária no Decênio 1998-2007

Notação utilizada na Tabela II: $S_{i}$ - i-ésimo semestre, M - Mestrado, D - Doutorado, Prof EC $C_{0 i}$ - i-ésimo Professor Estatutário a ser contratado, Prof $V C_{0 i}$ - i-ésimo Professor Visitante a ser contratado. Obs.: A partir de 1999 o então professor visitante Rainer Madejsky passou a ser professor estatutário (ProfEC $C_{02}$ ) em decorrência da aprovação no concurso público. 
[1] Área de Física - UEFS; Departamento de Física da UEFS, PubliFis, Feira de Santana - BA (1998).

[2] CONSEPE-UEFS; Processo de criação do Departamento de Física da UEFS, não publicado, Feira de Santana - BA (1998).

[3] CONSU-UEFS; Processo de implantação do Departamento de Física da UEFS, não publicado, Feira de Santana (2000);

[4] E. Cruz; Compêndio de Filosofia, Ed. Globo, Porto Alegre - RS (1940).

[5] A.A. Abramczuk; O mito da Ciência Moderna: Proposta de análise da Física como base de ideologia totalitária, Cortez/Autores Associados, São Paulo - SP (1981).

[6] Enciclopédia Mirador Internacional; Conhecimento, vol. 06, Encyclopaedia Britannica do Brasil Publicações, São Paulo - SP (1976).

[7] J.C. dos Santos Filho; A interdisciplinaridade na Universidade: relevância e implicações, Educação Brasileira 14 (29) 59-80, $2^{\circ}$ sem. (1992).

[8] M. Chauí; Vocação política e vocação científica da Universidade, Educação Brasileira 15 (31) 11-26, 2 ${ }^{\circ}$ sem. (1993).

[9] M.A. Andery et al; Para compreender a Ciência - uma perspectiva histórica, EDUC, Rio de Janeiro - RJ (1988).

[10] L.E.H. Trainor and M.B. Wise; From Physical Concept to Mathematical Structure: An Introduction to Theoretical Physics, University of Toronto Press, Canada (1981).

[11] S. Resende; A Física no Brasil, Estudos da SBF, 01 04-39 (1994).

[12] A.L. de R. Barros; Perspectivas em Física Teórica, Anais do Simpósio de Física em Homenagem ao $70^{\circ}$ Aniversário do Prof. Mário Schenberg, Instituto de Física da Universidade de São Paulo, São Paulo - SP (1987).

[13] Enciclopédia Mirador Internacional. Física 09, Encyclopaedia Britannica do Brasil Publicações, São Paulo - SP (1976).

[14] M.G. Ferri e S. Motoyama (Coord.); História das Ciências no Brasil, EPU/EDUSP, São Paulo - SP, (1979).

[15] J. Goldemberg; 100 anos de Física, Ciência e Sociedade, CBPF-II (02) (1973).

[16] S. Resende; A Física no Brasil, Boletim Informativo, 18 (02) 05-41 (1987).

[17] SBF; A Física no Brasil na próxima década, 3 v., Publicação da SBF, São Paulo - SP (1990).

[18] SBF, Estudo sobre o sistema de Bolsa de Produtividade em pesquisa do CNPq na área de Física e Astronomia, Boletim Informativo, 29 (01) 24-42 (1998).

[19] SBF, PACS_ 95.asc, revised 6/1995.

[20] A. de la H. Gascón; Coordenadas para la investigación Supradisciplinar, http://www.iieh.org/doc/doc200301220300.html;

[21] A.F.G. da Costa; Interdisciplinaridade: a Práxis da Didática Psicopedagógica, UNITEC, Rio de Janeiro - RJ (2000).

[22] A. Freire; Gramática Grega, Livraria Martins Fontes, São Paulo - SP (1987).

[23] Área de Física - UEFS; Plano de Capacitação e Atividades Docentes da Área de Física, $3^{\mathrm{a}}$ ed., PubliFis, Feira de Santana - BA (1996).

[24] UEFS; A Universidade em questão - I Relatório Síntese da Avaliação Institucional, Publicação interna, Feira de Santana - BA (1997).

[25] UEFS; Planejamento Estratégico Inicial - Universidade Estadual de Feira de Santana, Publicação interna, Feira de Santana - BA, (1997).

[26] Assessoria de Planejamento - UEFS; Boletim Institucional, vol. I - Legislação, Publicação interna, Feira de Santana BA (1997).

[27] UEFS; A Universidade em questão - O que se sugere no $1^{\circ}$ Relatório Síntese da Avaliação Institucional em Curso na
UEFS, Publicação interna, Feira de Santana - BA (1997).

[28] J. Leite Lopes; Ciência e Desenvolvimento, $2^{\mathrm{a}}$ ed., EDUFF, Rio de Janeiro - RJ (1987).

[29] P. Demo; Qualidade e modernidade da Educação Superior: discutindo questões de qualidade, eficiência e pertinência, Educação Brasileira 13 (27) 35-80, $2^{\circ}$ sem. (1991).

[30] L.M.T. Furlani; Autoridade do Professor: meta, mito ou nada disso?, Cortez/Autores Associados, São Paulo - SP (1988).

[31] M. S. Ribeiro, D.E. de M. Motta, e D.S. Freitas; A problemática do ensino de laboratório de Física na UEFS, Comunicação Oral, XII Encontro de Físicos do Norte-Nordeste, Fortaleza - CE, Sociedade Brasileira de Física (1994).

[32] E.S. Teixeira, A.J.S. dos Anjos, D.S. Freitas, D.E. de M. Motta, J.A. Miranda, e M.S. Ribeiro; Laboratórios didáticos de Física da UEFS: uma abordagem epistemológica, Comunicação em Painéis, I Congresso de Pesquisa das Universidades Estaduais da Bahia, Salvador - BA, Secretaria de Educação e Cultura do Estado da Bahia (1997).

[33] M.S. Ribeiro, D.S. Freitas e D.E. de M. Motta, O ensino de laboratório de Física na UEFS: considerações teóricopedagógicas, Sitientibus 16123 (1997).

[34] M.S. Ribeiro, D.S. Freitas e D.E. de M. Motta; A problemática do ensino de laboratório de Física na UEFS, Rev. Bras. Ens. Fis. 19444 (1997).

[35] Assessoria de Planejamento - UEFS; Planejamento Estratégico Participativo - Questão Estratégica 3: Como reestruturar física e administrativamente o Departamento?, Publicação interna, Feira de Santana - BA (1997).

[36] DEXA - UEFS; Planejamento Estratégico Participativo - Departamento de Ciências Exatas, Publicação interna, Feira de Santana - BA (1997).

[37] UEFS; Documento Geral de Planejamento Estratégico Participativo - UEFS, Publicação interna, Feira de Santana BA (1997).

[38] Área de Física - UEFS; Projeto do Anexo dos Laboratórios de Física do Modulo IV, PubliFis, Feira de Santana - BA (1998).

[39] Assessoria de Planejamento - UEFS; Programação Orçamentária - 1998: Departamento de Ciências Exatas, Publicação interna, Feira de Santana - BA (1997).

[40] UNB; Extensão - a universidade construindo saber $e$ cidadania, Documento final do I Encontro de Pró-Reitores de Extensão das Universidades Brasileiras (1987), Brasília (1989).

[41] Z.G.P. de Barros; A extensão universitária e o ensino de $1^{\circ}$ $e 2^{\circ}$ graus, Educação Brasileira, Ano II 5 273-287, $2^{\circ}$ sem. (1980).

[42] V. Garrafa; Extensão: do assistencialismo ao compromisso, Humanidades, Ano IV, 12 88-90 (1987).

[43] R. H. dos Reis; A institucionalização da extensão, Educação Brasileira 14 (28) 67-81 $1^{\circ}$ sem. (1992).

[44] H.L. Meirelles; Direito Administrativo Brasileiro, $13^{\mathrm{a}}$ ed., Revista dos Tribunais, São Paulo - SP (1987).

[45] UEFS; Planejamento Estratégico Inicial - Universidade Estadual de Feira de Santana, Publicação interna, Feira de Santana - BA (1997).

[46] UEFS; A Universidade em questão - Seminário de abertura da Avaliação Institucional, Anais, 18 a 22 de novembro, (1991).

[47] UEFS; A Universidade em questão - Projeto de Avaliação Institucional, Publicação interna, Feira de Santana - BA (1994).

[48] M.S.S. Graciani; O Ensino Superior no Brasil - a estrutura de poder na universidade em questão, $2^{\mathrm{a}}$ ed., Ed. Vozes, São Paulo - SP (1982). 